\title{
DIRECT TENSILE BEHAVIOR OF ULTRA HIGH PERFORMANCE FIBER REINFORCED CONCRETE (UHP-FRC) AT HIGH STRAIN RATES
}

\author{
Sukhoon Pyo ${ }^{1 *}$, Sherif El-Tawil ${ }^{2}$ and Antoine E. Naaman ${ }^{2}$ \\ ${ }^{1}$ New Transportation Systems Research Center, Korea Railroad Research Institute, 176 Railroad Museum Road, \\ Uiwang-si, Gyeonggi-do, 16105, South Korea \\ ${ }^{2}$ Department of Civil \& Environmental Engineering, University of Michigan, 2350 Hayward, G.G. Brown, \\ Ann Arbor, MI 48109-2125, USA \\ *Corresponding author, E-mail: shpyo@krri.re.kr, +82 31-460-5413
}

\begin{abstract}
This experimental study investigates the direct tensile behavior of ultra-high performance fiber reinforced concrete (UHP-FRC) at strain rates ranging from 90 to $146 / \mathrm{sec}$. The tests are conducted using a recently developed impact testing system that uses suddenly released strain energy to generate an impact pulse. Three fiber types were considered, a twisted fiber and two other types of straight fibers. Specimen impact response was evaluated in terms of first cracking strength, post cracking strength, energy absorption capacity and strain capacity. The test results indicate that specimens with twisted fibers generally exhibit somewhat better mechanical properties than specimens with straight fibers for the range of strain rates considered. All UHPFRC series tested showed exceptional rate sensitivities in energy absorption capacity, generally becoming much more energy dissipative under increasing strain rates. This characteristic highlights the potential of UHP-FRC as a promising cement based material for impact- and blastresistant applications.
\end{abstract}

Keywords: C. Mechanical Properties; C. Strain Effect; C. Tensile Properties; E. Fiber Reinforcement; E. High-Performance Concrete 


\section{INTRODUCTION AND MOTIVATION}

There is a wealth of published information about the high strain rate response of concrete and other cementitious composites in both compression and tension. For example, Tang et al. [1], Ross et al. [2], Tedesco and Ross [3] and Grote et al. [4] studied the compressive behavior of concrete at strain rates up to 1700 /sec. Körmeling and Reinhardt [5] and Ross [6] conducted direct tension tests of concrete at strain rates of up to 20 /sec, while Ross et al. [7] and Chen et al. [8] conducted dynamic splitting tension tests (dynamic Brazilian test). Xu et al. [9] performed drop-weight splitting tension tests on fiber reinforced concretes with different steel fibers to study their dynamic material properties. Brara et al. [10] conducted spalling tests using a split Hopkinson pressure bar (SPHB) and managed to achieve strain rates up to 120 /sec. Other high strain rate tensile tests were conducted by Lindholm and Yeakley [11], Nicholas [12], Li et al. [13], Cadoni et al. [14], Wang et al. [15], Li and Xu [16], Song et al. [17], Cadoni et al. [18], Kim et al. [19,20], Mechtcherine et al. [21] and Pyo and El-Tawil [22].

Ultra high performance fiber reinforced concrete (UHP-FRC) has recently gained much attention because of its extremely high pseudo-static mechanical properties [23-26]. UHP-FRC can achieve compressive strengths in excess of $150 \mathrm{MPa}$. When properly reinforced with steel fibers, it is capable of achieving tensile strain hardening behavior with strain at peak stress of up to two orders of magnitude greater than that of regular concrete [25] and exceptional energy absorption prior to fracture [27]. Although these properties suggest that the material has great potential for application in blast and impact resistance applications, there are very few published results about its properties at high strain rates. Among them are Habel and Gauvreau [28], who conducted drop weight tests on UHP-FRC bending specimens, and Millard et al. [29] who conducted 
flexural and shear high-speed loading test of UHP-FRC specimens using a drop-hammer testing apparatus, and Nöldgen et al. [30], who carried out high speed dynamic loading tests on UHPFRC using a spall version of the Hopkinson Bar. Furthermore, Parant et al. [31] carried out fourpoint bending test of UHP-FRC at high loading rates using a block-bar device. Fujikake et al. [32] investigated strain rate effects of UHP-FRC under tension using a uniaxial rapid tensile loading system loading rates ranging from 0.0001 to $50 \mathrm{~mm} / \mathrm{sec}$. Pyo et al. [33] carried out direct tension tests of UHP-FRC with different fibers at low to moderate rates ranging from 0.0001 to 0.1 /sec using a hydraulic servo-controlled testing machine.

To the best of the author's knowledge, there is a lack of published tests of UHPC in direct tension under high strain rates, which primarily motivated the work in this paper. In particular, two issues needed clarification: 1) will UHP-FRC retain its energy absorbing characteristics at high strain rates, and 2) maintain its strain hardening performance in tension? With these questions in mind, the primary objective of this effort is to experimentally characterize the direct tensile response of UPH-FRC under strain rates on the order of $10^{2} / \mathrm{sec}$ as a function of fiber characteristics. Since a new step up is employed, as outlined in Pyo and El-Tawil [22], a series of experimental and simulation-based parametric studies are conducted first to develop the optimal specimen geometry for the tests. The measured mechanical properties are then compared with those at low strain rates (obtained for the same UHP-FRC materials, as documented in Pyo et al. [33]) to build a broader picture of the effects of strain rate on fundamental material properties, including first cracking strength, post cracking strength, energy absorption capacity and strain capacity. 


\section{TEST SETUP}

The SHPB (Split Hopkinson Pressure Bar) and drop weight testing are typically used to characterize the impact behavior of concrete and other cementitious composites. However, both techniques require large open spaces and specialized testing methods, which have hindered their widespread use. To address these limitations, Kim et al. [34] proposed an alternative test setup that is more compact, simpler and cheaper to use than the SHPB, especially for testing concrete in tension. The test device was further refined by Tran and Kim [35, 36] and Kim et al. [37] and designated Strain Energy Frame Impact Machine (SEFIM). As discussed next, additional refinements by Pyo and El-Tawil [22] resulted in a modified SEFIM, termed M-SEFIM.

The way by which M-SEFIM operates is straightforward. Referring to Figure 1: first, a load is applied to a short pull bar. The tensile force is transmitted through a coupler to a bridging member, which loads two parallel energy bars, where elastic strain energy is stored. After sudden fracture of the coupler under increasing load, the stored elastic energy is transferred to a load transfer member to which a concrete specimen is attached. The resulting load pulse is channeled through the specimen into a transmitter bar.

Pyo and El-Tawil [22]'s key modification for M-SEFIM over SEFIM is to ensure that the transmitter bar is long enough to allow the full hardening and softening loading regimes of UHPFRC to be captured. The extra-long extent of these regimes complicates the testing process and requires special considerations as outlined in Pyo and El-Tawil [22]. Brass was selected for the transmitter bar, which was $1.55 \mathrm{~m}$ in length. Compared to steel, brass has a slower wave speed, 
which reduces the required transmitter bar length as explained in Pyo and El-Tawil [22]. Figure 1 shows the concept of M-SEFIM and Figure 2a shows M-SEFIM as built.

As done in conventional SHPB testing, a strain gage attached to the transmitter bar captures the stress in the specimen. The stress signal obtained from the strain gage is amplified and conditioned using a signal amplifier (VISHAY 2310B) and then recorded using an oscilloscope. Strain history in the specimen during impact testing is evaluated using the digital image correlation (DIC) technique after recording images of the specimen using a high speed camera (Photron SA5) at the rate of 75,000 frames per second. Extensive computational studies using the model discussed next and documented in Pyo and El-Tawil [22] show that M-SEFIM has the capability to accurately capture the material properties of UHP-FRC under direct tension loading at high strain rates ranging from 90 to 146 /sec.

\section{SIMULATION OF TEST SETUP}

As documented in Pyo and El-Tawil [22], a series of simulations were conducted using LSDYNA [38]. developed a simulation model to evaluate and refine the response of M-SEFIM. The model was exercised on the LS-DYNA platform and run within an explicit integration Eight-node solid elements were used to model M-SEFIM, and interpenetration between parts in the system was prevented by using the contact features in LS-DYNA. Tensioning of the pull bar was performed by applying displacement control at the end of the pull bar. An isotropic elastic-plastic material model, which can represent separate stress versus plastic strain responses for compression and tension, was used to model the behavior of UHP-FRC. The coupler was represented using a mixed anisotropic-kinematic hardening plasticity material model. 
Element erosion was activated when a pre-specified plastic strain was reached to represent fracture of the specimen and coupler. The specimen's response was then computed as it would from the experiment, i.e. by measuring strain in the transmitter bar and converting that to stress, whereas strain was computed from the displacements of top and bottom points in the specimen's gage length. Figure 2b shows details of the model, in comparison to the as-built device shown in Figure 2a. Further information about the model can be found in Pyo and El-Tawil [22].

\section{SPECIMEN PREPARATION}

To ensure broad applicability of the data developed in this work, the specimens used in this study are made compatible with a previous research effort by Pyo et al. [33] that studied UHP-FRC response at lower strain rates ranging from 0.0001 to 0.1 /sec. That way, the data from both related studies covers a wide range of strain rates, allowing for a broader and more comprehensive picture of strain rate sensitivity to emerge. To achieve this objective, the specimens used in this study have the same cross-section as specimens tested in the previous study, as shown in Figure 3. Also, the UHP-FRC mixes used in this work are the same as those used in Pyo et al. [33]. Table 1 shows an example of mix proportions of UHP-FRC, and the details of the mix proportions of UHP-FRC with different fiber volume fractions can be found in Pyo et al. [33], along with a description of the mixing technique. Table 2 lists the mechanical properties of the three steel fibers used in this study. It should be noted that the tensile strength of the steel fibers are quasi-static values and their properties are expected to be higher under impact loading conditions as discussed in Section 7.3. All specimens were tested in dry condition at the age of 28 days at least, after 26 days of curing in a water tank. Random speckle patterns (for the DIC technique) were applied to the surface of the specimens by spraying white and black paints. 
DIC technique is an optical, non-contact technique, and used to measure strain of the surface of a specimen in this research. Pyo [39] and El-Tawil [22] discusses the DIC method used and provides details of its application.

\section{SPECIMEN NAMING SCHEME AND DATA ANALYSIS}

The same naming scheme used in Pyo et al. [33] is employed here as well, where different fibers are designated by their type, diameter and length, e.g. T-0.3-25 is a twisted fiber with $0.3 \mathrm{~mm}$ nominal diameter and $25 \mathrm{~mm}$ long, and S-0.2-25 is a straight fiber with $0.2 \mathrm{~mm}$ diameter and 25 mm long. The nominal diameter of a twisted fiber is that of the wire from which it is manufactured. Seven series, with 3 tensile specimens each, were prepared and tested as shown in Table 3. Each series is designated by fiber type as discussed above and appended with a number that reflects the volume fraction of the fiber. The rate sensitivity of these materials in direct tension was evaluated in terms of their first cracking strength $\left(\sigma_{v e}\right)$, post cracking strength $\left(\sigma_{p e}\right)$, energy absorption capacity $(g$ ) and strain capacity, that is the strain value at post cracking strength $\left(s_{p_{z}}\right)$ as can be seen in Figure 4. It should be noted that $g$ is the area under stress-strain curve up to $\sigma_{u}\left(=9.95 \sigma_{w o}\right.$ on the descending branch), as done in Pyo et al. [33]. Dynamic increase factors (DIFs), the ratios of dynamic to static responses, are computed for four parameters $\left(\sigma_{\sigma e}, \sigma_{p e}, g, s_{p \varepsilon}\right)$ to illustrate the effect of strain rate on strength and other material parameters. In this study, the values measured at the lowest strain rate of 0.0001/sec from Pyo et al. [33] are considered to be static responses.

The strain rate in the test specimen is calculated as [40] 


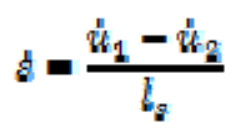

where $l_{a}$ is the gage length of the specimen, and $\dot{u}_{1}$ and $\dot{u}_{2}$ are the velocities at both ends of the

gage length. The average strain rate was calculated by averaging strain rate over the duration of loading, as done in Pyo and El-Tawil [22]. Figure 5 shows an example of the recorded stress and strain data for a T-0.3-25-1\% specimen. In this example, the strain rate is calculated to be 119 /sec. Figure 6 shows the average stress-strain response in comparison with the raw stress-strain responses of multiple specimens. The curve averaging process is discussed in detail in Pyo et al. [33]. It should be noted, and this was generally observed throughout the test program, that specimen-to-specimen variability is reasonably low for all parameters considered in this work.

\section{SELECTION OF SPECIMEN LENGTH}

Specimen length is an important variable. Specimens that are too short or long may influence measurement of quantities sought in the experiments. Therefore the finite element model developed by Pyo and El-Tawil [22] is used here to evaluate the effect of specimen length $(l$ in Figure 1) on measured response. The red dashed line in Figure 7 is the assigned stress-strain curve for UHP-FRC under tension, which compares reasonably to the measured uniaxial responses of UHP-FRC specimens as reported by Pyo et al. [33]. The predicted stress-strain responses based on the simulation results of UHP-FRC under uniaxial tension for various specimen lengths are shown in Figure 7. Figures 8 and 9 show examples of how UHP-FRC specimens of various length fare in both simulations and experiments, respectively. It is clear from Figure 7 that no significant difference can be found in the computed stress-strain responses 
of the various specimens and that all compare well with the analytically specified stress-strain response.

Figure 10 illustrates the averaged stress-strain responses of UHP-FRC with various specimen lengths as obtained from the experiments. Table 3 summarizes the details of the test results. As seen in the simulation studies, the effect of specimen length on stress-strain response is minor. Figure 11 shows the computed DIF versus specimen length for various mechanical properties: first cracking strength, post cracking strength, energy absorption capacity and strain capacity. Similar to the overall stress-train curves, no clear trend can be found for first cracking strength and strain capacity associated with increasing specimen length from 55 to $65 \mathrm{~mm}$. However, DIFs for post cracking strength and energy absorption capacity increase by $15 \%$ and $28 \%$, respectively, as specimen length increases from 55 to $65 \mathrm{~mm}$.

The effect of specimen length on the strain rate recorded from both simulations and experiments is illustrated in Figure 12. Three trends are evident from the figure. First, there is large scatter in the experimental strain rate values. Second, simulation results for strain rate match reasonably well with their measured counterparts, especially given the large scatter. Third, both simulation and experimental data suggest that strain rates decrease as specimen length increases. While both simulation and experimental studies quantify the effect, the trend is indeed expected, i.e. the strain rate will decrease linearly as the gage length of the specimen increases, as suggested in Equation 1. 
Dynamic testing requires that a short specimen be used to ensure that it is uniformly loaded during the experiment $[41,42]$. On the other hand, a gage length that is too short compared to the least size of the constituents of the material being tested does not permit meaningful measurement of strain. For UHP-FRC specimens and the given experimental program, which employs $25 \mathrm{~mm}$ long fibers, specimen length was selected to be $55 \mathrm{~mm}$. Based on the discussion above, this length was deemed long enough for the fiber length and yet short enough to avoid non-uniform loading during the experiments.

\section{EVALUATION OF EXPERIMENTAL RESULTS}

Table 3 summarizes test results including strain rates and the four basic parameters computed

from the test data: $\sigma_{\varepsilon \varepsilon}, o_{p \varepsilon}, g$, and $\varepsilon_{p \varepsilon}$. The Table shows that strain rates ranging from 90 to 146 /sec are achieved. The DIF values are also listed in Table 3. The average tensile stress-strain curves for each series with different types of fiber and volume fractions are plotted in Figure 13. The stress-strain curves with lower strain rates obtained by Pyo et al. [33] are also plotted in Figure 13 to allow a direct comparison of UHP-FRC responses under various loading rates. There is clear evidence from all test series described in Figure 13 that UHP-FRC specimens loaded at high strain rate show exceptional enhancement in both peak strength and strain capacity compared to specimens loaded at low strain rates $(<0.1 / \mathrm{sec})$ regardless of fiber type. More importantly, the energy absorption capacity of UHP-FRC specimens under impact loading is remarkable (Figure 14c), about an order or magnitude higher than their quasi-static counterparts. The latter observation suggests that UHP-FRC is likely a highly promising cement based material for impact and blast resistance applications. 
Figure 14 depicts the effect of two parameters, fiber type and fiber volume fraction, on the strain rate sensitivity of UHP-FRC. Since the strain rate is bounded within a relatively narrow band, values that are averaged across all strain rates are used in Figure 14. From a qualitative perspective, Figure 14 suggests that increasing fiber volume fraction leads to an increase in first cracking strength, post cracking strength, energy absorption capacity and strain capacity for all fiber cases (S-0.2-25, S-0.4-25 and T-0.3-25). In general, all the parameters summarized in Table 3 show significant rate sensitivities.

Figure 9a shows the captured cracking patterns for specimen T-0.3-25-1\% tested at 144.6 /sec strain rate. The figure clearly shows that the specimen exhibits multiple cracking. This is also evident in the computed stress strain curves, where hardening behavior after first cracking is observed. Multiple cracking with strain hardening behavior was observed in all specimens, even at $1 \%$ fiber content, and confirms observations made earlier for high performance fiber reinforced cementitious composites by Kim et al. [34] for impact loaded specimens. Examples of the progressive development of multiple cracking can be found in Pyo [39].

\subsection{Effect of fiber type and aspect ratio}

As seen in the tests at lower strain rate reported in Pyo et al. [33], the twisted fiber series show somewhat better performance than the straight fiber series at high strain rates (see Figure 14). As surmised by Pyo et al. [33] for low strain rates, it is believed that the additional anchorage effect associated with the untwisting action that occurs during pullout is the reason for the improved behavior. The enhanced behavior seen in twisted fiber specimens is not across the board. For example, the T-0.3-25 and the S-0.2-25 fibers show similar $\sigma_{p e}$ and $\varepsilon_{p e}$ for a volume fractions up 
to $2 \%$. However, $g$, is much higher in the former than the latter, i.e. T-0.3-25-2\% shows $47 \%$ higher energy absorption capacity than S-0.2-25-2\% at high strain rate loading. The higher aspect ratio, $l_{f} / d_{f}$, of the S-0.2-25 fibers, which translates into more fibers per unit volume, and its higher specific surface for bond, appear to compensate for the mechanical anchorage action of the twisted fibers when it comes to $\sigma_{p \varepsilon}$ and $\varepsilon_{p e}$, but not for energy absorption capacity.

As expected, straight fibers with higher aspect ratio, S-0.2-25, show generally better performance than corresponding straight fibers with lower aspect ratio, S-0.4-25. For example, the S-0.2-25$2 \%$ case shows $10 \%, 40 \%$ and $77 \%$ higher post cracking strength, energy absorption capacity and strain capacity, respectively, than S-0.4-25-3\% under impact loading. These observations suggest that the fiber aspect ratio is a critical factor not only at low strain rates but also at higher strain rates.

The general trend from the test data under impact loading is that the post-cracking stress and corresponding strain increase substantially under impact loading for all fiber types. The increase is significantly more important for energy absorption capacity. For example, the strain capacity DIF for the $\mathrm{T}-0.3-25-2 \%$ series is 2.56 for impact (averaged across all strain rates achieved in the tests), whereas the corresponding energy absorption DIF for the same series is 11.55 .

\subsection{DIF}

Overall, the DIF results in Table 3 along with the plots in Figures 15 and 16 highlight the impact resistance of UHP-FRC under tensile loading. DIF was evaluated for four key parameters, first cracking strength, post cracking strength, energy absorption capacity and strain capacity. Plots of 
DIF versus strain rate for different fiber types and volume fractions are compared in Figure 16. The increases in DIF of the four parameters follow a log-linear relationship at lower strain rates and rise exponentially at high strain rates. This follows general trends for regular concrete under tension, where the DIF for tensile strength increases mildly up to strain rates between 1 or 30/sec then increase much rapidly thereafter [43-46].

The S-0.4-25-3\% series shows the highest rate sensitivity for post cracking strength. The DIF for this parameter is 4.3 on average. In contrast, the S- $0.2-25-2 \%$ series shows the lowest rate sensitivity for post cracking strength, i.e. 3.0 on average. The T-0.3-25-1\% series shows the highest rate sensitivity for strain capacity. The DIF for this parameter is 3.2 on average. In contrast, the S-0.2-25-2\% series shows the lowest rate sensitivity for strain capacity, i.e. 2.1 on average. It appears that the range is narrow enough to attribute the differences to experimental scatter.

It should be noted, as can be seen in Figures 16e and 16f, that twisted fibers show a somewhat higher increase in energy absorption capacity DIF than straight fibers. However, it is noteworthy that straight fiber series still exhibit impressive increases in energy absorption capacity. It is difficult to draw a firm conclusion about the increase in strain capacity due to scatter of data in strain capacity.

\subsection{Comparison with theoretical predictions}

Experimental data for high strain rates is compared with theoretical predictions for cement based composites reinforced with short discontinuous fibers to assess whether the theoretical 
predictions are applicable to impact loading situations. According to Naaman [47], the post cracking strength of composites reinforced with short discontinuous fibers is proportional to the fiber aspect ratio and volume fraction as follows:

$$
\sigma_{p q}=\lambda r_{\mathrm{eq}} V_{f}\left(\zeta_{f} / d_{f}\right)
$$

where $\lambda$ is a factor equal to the product of several coefficients that account for average pullout length, group reduction effect, and fiber orientation effect. $\tau_{e q}$ is the equivalent bond strength. The product $V_{f}\left(l_{f} / d_{f}\right)$ is termed the fiber reinforcing index. Moreover, the surface energy of pull-out, which gives a good estimate of the fracture energy in the type of tensile tests carried out here can be put in the following form [48]:

$$
\psi_{g}=\zeta \tau_{e q} V_{t}\left(\zeta_{f}^{2} / d_{f}\right)
$$

where $\zeta$ is the product of $\lambda$ in Equation (2) and the ratio of average bridging stress to the maximum post-cracking stress over the expected maximum pull-out length. It can be thus observed that the fracture energy varies with the square of the fiber length or with the product of the fiber length by the reinforcing index. Furthermore, the average tensile stress, $\sigma_{f y e}$, in the fiber at maximum stress in the composite can be calculated by Equation (4) following Wille et al. [27]:

$$
\sigma_{f \gamma \varepsilon}=\frac{\sigma_{p r}}{\phi \cdot V_{f}}
$$

where, $\phi$ is a fiber orientation factor, taken 0.9 for all series following Wille et al. [27].

Figures 17 and 18 illustrate the measured post-cracking strength versus the reinforcing index, and energy absorption capacity versus the product of the fiber length and the reinforcing index, 
respectively. The data is plotted for 3 strain rates $(0.0001 / \mathrm{sec}, 0.1$ /sec and impact) and for both twisted and straight fibers. The linear trend predicted by Equation 2 is clearly evident in Figure 17 for all strain rates. Similarly, as predicted by Equation 3, the energy absorption capacity increases linearly with $v_{f}\left(b_{f}^{2} / d_{f} d_{f}\right)$ for all 3 strain rates considered and for both fiber types. The higher slopes associated with twisted fibers in Figures 17(b) and 18(b) compared to smooth fibers in Figures 17(a) and 18(a), respectively are an indication that fiber twisting enhances the mechanical properties of UHP-FRC, especially at higher strain rates. The effect is modest for post cracking strength, where the coefficient at impact loading increases from 19.01 (smooth) to 26.18 (twisted), a $37.7 \%$ increase (see Figure 17). The effect is substantially larger for energy absorption; the coefficient at impact loading increases from 8.26 (smooth) to 18.8 (twisted), a 227.6\% increase (see Figure 18). It is not clear from Figures 17 and 18 how $\tau_{o q}$ by itself affects the observed strain rate sensitivities since it is bundled with $\lambda$ and $\zeta$ in Eqs. (2) and (3), respectively. The effects of these two parameters and their interactions with $\tau_{\varepsilon q}$ can only be identified through future research involving fiber pullout testing.

Table 4 summarizes fiber tensile stress and equivalent bond strength for impact conditions for different fiber types and volume fractions. Fiber tensile stress under lower strain rates can be found in Pyo et al. [33]. It is clear that $o_{f w o}$ depends on fiber type but is somewhat independent of fiber volume fraction. Smooth fibers with high aspect ratio (S-0.2-25) and twisted fibers (T0.3-25) show higher $\sigma_{f p m}$ than smooth fibers with low aspect ratio (S-0.4-25), indicating that fibers are better mobilized in those situations. The high values of $\sigma_{f w}$ suggest that the fibers are heavily loaded during impact. In fact, Table 4 shows that the average fiber stress, $\sigma_{f y e}$, exceeds 
the static tensile strength as listed in Table 2, suggesting that fibers likely see high demands under impact conditions. A close examination of the tested specimens did not clearly show fiber breakage, which implies that Equation 4 may not fully capture the mechanics of the impact situation and that some other mechanisms may be at play under impact conditions. Until these mechanisms are clarified through new research, the numbers in Table 4 suggest at least one conclusion, that is, it is necessary to use high strength fibers with UHP-FRC to ensure good impact response.

Also of note from Table 4 is that $\lambda \tau_{\text {rq }}$ is independent of fiber volume fraction and aspect ratio for smooth fibers. Twisted fibers, however, showed some dependency on fiber volume fraction and exhibited, on average, a higher equivalent bond strength than smooth fibers. Unlike the lower strain rate cases in Pyo et al. [33], where $\lambda x_{0 q}$ was seen to be independent of fiber type, the higher numbers for twisted fibers seen here is likely a manifestation of the greater strain rate sensitivity generally seen in specimens with twisted fibers at high strain rates.

\subsection{Discussion}

Many engineering materials become stronger, but more brittle, and less energy absorbent, when loaded at high strain rates. Yang and Li [49] found that the tensile strength of Engineered Cementitious Composite (ECC) reinforced with polyvinyl alcohol (PVA) fibers doubled whereas its strain capacity decreased from $3 \%$ to $0.5 \%$ as strain rate increased from $10^{-5}$ to $10^{-1} / \mathrm{sec}$. Sun et al. [50] concluded that the failure strain of E-Glass/epoxy composites decreased from $16.8 \%$ to 9.6\% as the strain rate increased to 1600 /sec. Smerd et al. [51] carried out high strain rate tensile testing of aluminum alloys and found out that energy absorption capacity under high strain rates 
decreased by up to half of that under quasi-static cases. In contrast, the UHP-FRC material studied in this paper exhibits different trends. It becomes stronger, more ductile and energy absorbent as strain rate increases. These substantial, and indeed remarkable, improvements at high strain rates suggest that UHP-FRC is a highly damage tolerant material that is well suited for mitigation of blast and impact hazards.

It is important to note that the specimens used in this research have preferential fiber alignment with most fibers aligned along each specimen's major axis. Such alignment was unavoidable given the specimen sizes and fiber lengths used in this work and the constraints on specimen size imposed by the test setup. It is acknowledged that randomly aligned fibers, as would occur in a larger UHP-FRC structure, could impact the results outlined in this work, and is an issue that deserves further study.

\section{CONCLUSION}

This experimental study investigated strain rate effect of UHP-FRC under direct tension using a recently developed impact testing system that uses suddenly released strain energy to generate an impact pulse. A proper specimen length (from $55 \mathrm{~mm}$ to $65 \mathrm{~mm}$ ) was identified based on the series of computational and experimental parametric studies. The rate sensitivity of UHP-FRC specimens with three different types of steel fibers, three different lengths, and three different volume fractions was evaluated in terms of their first cracking strength, post cracking strength, energy absorption capacity and strain capacity under direct tensile loading. The experimental study utilized specimens that were similar in cross-section and material properties to those used in a related study [33] that focused on pseudo-static loading. That way, the data from both 
studies covered a large range of strain rates, allowing for a more comprehensive picture of strain rate sensitivity to emerge. The observations and findings of this study can be summarized as follows:

1. Strain rates of 90 to $146 / \mathrm{sec}$ were achieved in this study. Crack localization and eventual failure occurred within the gage length in all UHP-FRC specimen and both hardening and softening segments of the stress-strain response were captured. These results demonstrate M-SEFIM's unique capability to conduct impact testing for UHP-FRC and other cementitious composites under direct tension loading, while requiring a minimal laboratory footprint.

2. The general trend from the test data under impact loading is that strain capacity increases substantially under impact loading for all fiber types. Post cracking strength and energy absorption capacity increase greatly under impact loading.

3. Analysis of the experimental data shows that fiber aspect ratio and twisting play important roles in the response of UHP-FRC under tension at high strain rates. Specimens with more slender smooth fibers and with twisted fibers were better able to mobilize the fibers than specimens with stubbier fibers - as evidenced by higher $\pi_{\gamma_{\text {v }}}$ values. Moreover, specimens with twisted fibers saw greater increases in post cracking strength and energy absorption capacity compared to those with smooth fibers.

4. Extremely high values of $\sigma_{f p e}$ (maximum stress in the fiber at failure of the composite) were computed, suggesting that the fibers are highly loaded during impact. The high $\sigma_{f p o}$ values suggest the need to use high strength fibers in UHP-FRC to achieve good performance under impact. 
5. As with other cement based materials, UHP-FRC exhibits log-linear increases in the DIFs associated with post cracking strength under low strain rates and dramatic increases in DIFs at high strain rates. Because of the material's unique strain hardening behavior under high strain rate, this trend also translates directly to energy dissipation capacity. These substantial, and indeed remarkable, improvements in mechanical properties at high strain rates suggest that UHP-FRC is a highly damage tolerant material that is well suited for mitigation of blast and impact hazards.

This study did not investigate material response at intermediate strain rates, around $10^{\circ} / \mathrm{sec}$. Such data, when available, will fill the gap between the data at low strain rate in Pyo et al. [33] and the new data in the current study. As Fujikake et al. [32] investigated tensile behavior of UHP-FRC under high strain rates up to $5.0 \times 10^{-1} / \mathrm{sec}$, a servo-controlled rapid loading machine could possibly be used to fill the gap.

\section{ACKNOWLEDGMENTS}

The research described herein was sponsored by the National Science Foundation under Grant No. CMS 0928193 and the University of Michigan, Ann Arbor. The first author was partially supported by a grant from R\&D Program of the Korea Railroad Research Institute, Republic of Korea. The opinions expressed in this paper are those of the authors and do not necessarily reflect the views of the sponsors.

\section{REFERENCES}


[1] T. Tang, L.E. Malvern, D.A. Jenkins, Rate effects in uniaxial dynamic compression of concrete, J. Eng. Mech. 118 (1992) 108-124.

[2] C.A. Ross, J.W. Tedesco, S.T. Kuennen, Effects of strain rate on concrete strength, ACI Mater. J. 92 (1995) 37-47.

[3] J.W. Tedesco, C.A. Ross, Strain-rate-dependent constitutive equations for concrete, ASME J. Press. Vessel Technol. 120 (1998) 398-405.

[4] D.L. Grote, S.W. Park, M. Zhou, Dynamic behavior of concrete at high strain-rates and pressures: I. Experimental characterization, Int. J. Impact Eng. 25 (2001) 869-886.

[5] H.A. Körmeling, H.W. Reinhardt, Strain rate effects on steel fibre concrete in uniaxial tension, Int. J. Cem. Compos. Lightweight Concr. 9 (1987) 197-204.

[6] C.A. Ross, Split Hopkinson pressure bar tests, Final Report, Air Force Engineering and Services Center, Tyndall AFB, Fl, ESL-TR-88-82 (1989).

[7] C.A. Ross, P.Y. Thompson, J.W. Tedesco. Split Hopkinson pressure bar tests on concrete and mortar in tension and compression, ACI Mater. J. 86 (1989) 475-481.

[8] R. Chen, Y. Liu, X. Guo, K. Xia, F. Lu, Dynamic tensile properties of steel fiber reinforced concrete, In: Dynamic Behavior of Materials. Springer, New York, 1 (2011) 37-42.

[9] Z. Xu, H. Hao, H.N. Li, Dynamic tensile behaviour of fibre reinforced concrete with spiral fibres, Mater. Des. 42 (2012) 72-88.

[10] A. Brara, F. Camborde, J.R. Klepaczko, C. Mariotti, Experimental and numerical study of concrete at high strain rates in tension, Mech. Mater. 33 (2001) 33-45.

[11] U.S. Lindholm, L.M. Yeakley, High strain-rate testing: Tension and compression, Exp. Mech. 8 (1968) 1-9. 
[12] T. Nicholas, Tensile testing of materials at high rates of strain, Exp. Mech. 21 (1981) 177185.

[13] M. Li, R. Wang, M.B. Han, A Kolsky bar: tension, tension-tension, Exp. Mech. 33 (1993) 7-14.

[14] E. Cadoni, K. Labibes, C. Albertini, M. Berra, M. Giangrasso, Strain-rate effect on the tensile behaviour of concrete at different relative humidity levels, Mater. Struct. 34 (2001) 21-26.

[15] Z.L. Wang, Y.S. Liu, R.F. Shen, Stress-strain relationship of steel fiber-reinforced concrete under dynamic compression, Constr. Build. Mater. 22 (2008) 811-819.

[16] W. Li, J.Xu, Impact characterization of basalt fiber reinforced geopolymeric concrete using a 100-mm-diameter split Hopkinson pressure bar, Mater. Sci. Eng. A 513 (2009) 145-153.

[17] B. Song, K. Connelly, J. Korellis, W.Y. Lu, B.R. Antoun, Improved Kolsky-bar design for mechanical characterization of materials at high strain rates, Meas. Sci. Technol. 20 (2009) 115701.

[18] E. Cadoni, A. Meda, G.A. Plizzari, Tensile behavior of FRC under high strain-rate, Mater. Struct. 42 (2009) 1283-1294.

[19] D.J. Kim, K. Sirijaroonchai, S. El-Tawil, A.E. Naaman, Numerical simulation of the Split Hopkinson Pressure Bar test technique for concrete under compression, Int. J. Impact Eng. 37 (2010) 141-149.

[20] N.T. Tran, T.K. Tran, D.J. Kim, Direct tensile response of ultra-high-performance fiberreinforced concretes at high strain rates, Cem. Concr. Res. 69 (2015) 72-87. 
[21] V. Mechtcherine, O. Millon, M. Butler, K. Thoma, Mechanical behaviour of strain hardening cement-based composites under impact loading, Cem. Concr. Compos. 33 (2011) 1-11.

[22] S. Pyo, S. El-Tawil, Capturing the strain hardening and softening responses of cementitious composites subjected to impact loading, Constr. Build. Mater. 81 (2015) 276283.

[23] P. Rossi, Ultra High Performance Concretes. Concr. Inter. 30 (2008) 31-34.

[24] B.A. Graybeal, Ultra-High Performance Concrete, Report No. FHWA-HRT-11-038, Federal Highway Administration, Washington, DC, 2011.

[25] A.E. Naaman, K. Wille, The path to ultra-high performance fiber reinforced concrete (UHP-FRC): Five decades of progress, In: Proceedings of Hipermat 3rd International Symposium on UHPC and Nanotechnology for High Performance Construction Materials. Kassel: Kassel University Press, 2012. p. 3-16.

[26] K. Wille, A.E. Naaman, S. El-Tawil, G.J. Parra-Montesinos, Ultra-high performance concrete and fiber reinforced concrete: Achieving strength and ductility without heat curing, Mater. Struct. 45 (2012) 309-324.

[27] K. Wille, S. El-Tawil, A.E. Naaman, Properties of strain hardening ultra high performance fiber reinforced concrete (UHP-FRC) under direct tensile loading. Cem. Concr. Compos. 48 (2014) 53-66.

[28] K. Habel, P. Gauvreau, Response of ultra-high performance fiber reinforced concrete (UHPFRC) to impact and static loading, Cem. Concr. Compos. 30 (2008) 938-946. 
[29] S.G. Millard, T.C.K. Molyneaus, S.J. Barnett, X. Gao, Dynamic enhancement of blastresistant ultra high performance fibre-reinforced concrete under flexural and shear loading, Int. J. Impact Eng. 37 (2010) 405-413.

[30] M. Nöldgen, W. Riedel, K. Thoma, E. Fehling, Properties of ultra high performance concrete (UHPC) in tension at high strain rates, In: van Mier JGM, Ruiz G, Andrade C, Yu RC, Zhang XX, editors. VIII International Conference on Fracture Mechanics of Concrete and Concrete Structures, 2013; p. 1-13.

[31] E. Parant, P. Rossi, E. Jacquelin, C. Boulay, Strain rate effect on bending behavior of new ultra-high-performance cement-based composite, ACI Mater. J. 104 (2007) 458-463.

[32] K. Fujikake, T. Senga, N. Ueda, T. Ohno, M. Katagiri, Effects of strain rate on tensile behavior of reactive powder concrete, J. Adv. Concr. Tech. 4 (2006) 79-84.

[33] S. Pyo, K. Wille, S. El-Tawil, A.E. Naaman, Strain rate dependent properties of ultra high performance fiber reinforced concrete (UHP-FRC) under tension, Cem. Concr. Compos. 56 (2015) 15-24.

[34] D.J. Kim, K. Wille, S. El-Tawil, A.E. Naaman, Testing of cementitious materials under high-strain-rate tensile loading using elastic strain energy, ASCE J. Eng. Mech. 137 (2011) $1-8$.

[35] T.K. Tran, D.J. Kim, Strain energy impact test machine (SEFIM), J. Adv. Concr. Technol. 10 (2012) 126-136.

[36] T.K. Tran, D.J. Kim, Investigating direct tensile behavior of high performance fiber reinforced cementitious composites at high strain, Cem. Concr. Res. 50 (2013) 62-73.

[37] D.J. Kim, S. El-Tawil, A.E. Naaman, Impact test apparatus by using energy frame, South Korea Patent 10-1212646, 10 December 2012. 
[38] J.O. Hallquist, LS-DYNA user's manual, P Livermore software technology corporation, 2000.

[39] S. Pyo, Characteristics of ultra high performance concrete subjected to dynamic loading, Ph.D. Dissertation, University of Michigan, Ann Arbor, 2014.

[40] G.T. Gray, Classic split-hopkinson pressure bar testing. American Society for Metals, ASM Handbook Vol. 8 - Mechanical Testing and Evaluation, 2000. p. 462-476.

[41] G. Ravichandran, G. Subhash, Critical appraisal of limiting strain rates for compression testing of ceramics in a split Hopkinson pressure bar, J. Am. Ceram. Soc. 77 (1994) 263267.

[42] W. Chen, B. Song, Split Hopkinson (Kolsky) bar: design, testing and applications, Springer, New York, 2011.

[43] L.J. Malvar, J.E. Crawford, Dynamic increase factors for concrete, In: Twenty-Eighth DDESB Seminar. Orlando, FL, 1998.

[44] S. Hentz, F.V. Donzé, L. Daudeville, Discrete element modelling of concrete submitted to dynamic loading at high strain rates, Comput. Struct. 82 (2004) 2509-2524.

[45] J. Leppanen, Concrete subjected to projectile and fragment impacts: Modelling of crack softening and strain rate dependency in tension, Int. J. Impact Eng. 32 (2006) 1828-1841.

[46] S. Pyo, S. El-Tawil, Crack velocity-dependent dynamic tensile behavior of concrete, Int. J. Impact Eng. 55 (2013) 63-70.

[47] A.E. Naaman, Engineered Steel Fibers with Optimal Properties for Reinforcement of Cement Composites, J. Adv. Concr. Technol. 1 (2003) 241-252.

[48] A.E. Naaman, Toughness, ductility, surface energy and deflection-hardening FRC composites, In: Proceedings of the JCI international Workshop on Ductile Fiber 
Reinforced Cementitious Composites (DFRCC) - Application and Evaluation (DFRCC-02). Takayama, Japan, 2002. p. 33-57.

[49] E. Yang, V.C. Li, Rate dependence in engineered cementitious composites, In: Proceedings, HPFRCC-2005 international workshop. Honolulu, Hawaii, USA, 2005.

[50] B. Sun, F. Liu, B. Gu, Influence of the strain rate on the uniaxial tensile behavior of 4-step 3D braided composites, Compos. Part B: Appl. Sci. Manuf. 36 (2005) 1477-1485.

[51] R. Smerd, S. Winkler, C. Salisbury, M. Worswick, D. Lloyd, M. Finn, High strain rate tensile testing of automotive aluminum alloy sheet, Int. J. Impact Eng. 32 (2005) 541-560. 

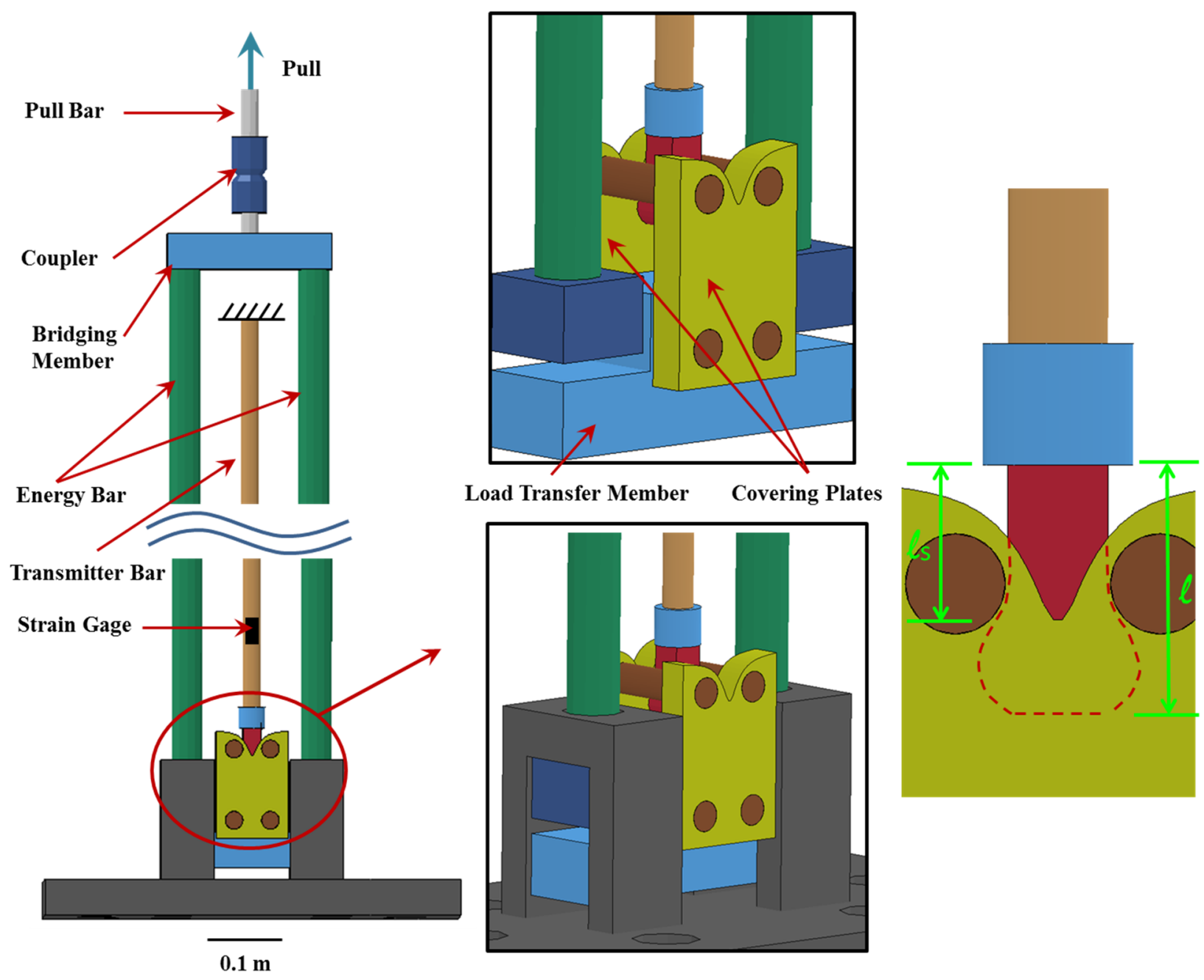

Figure 1. Conceptual description of the modified impact testing system (M-SEFIM) 


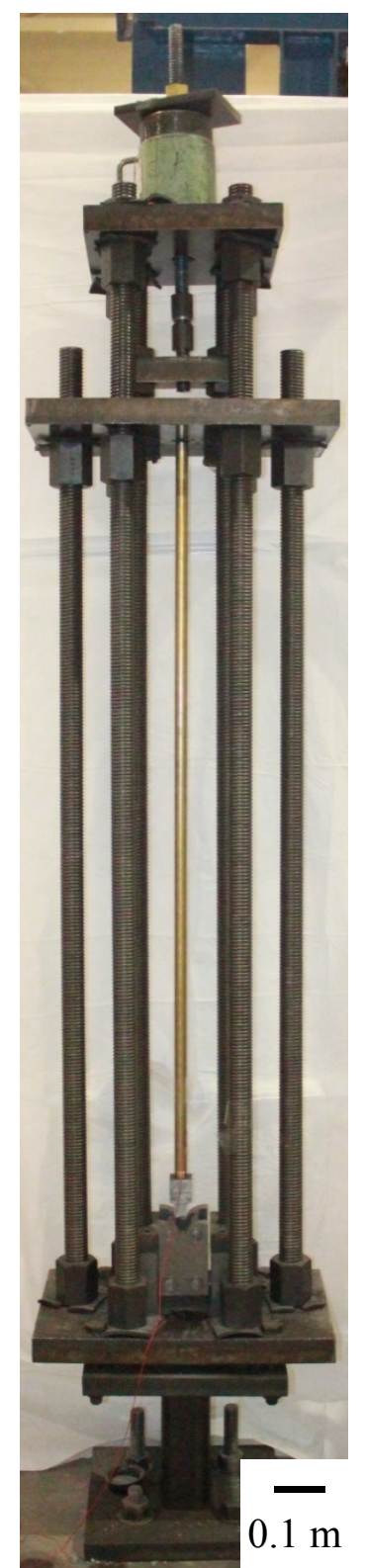

(a)

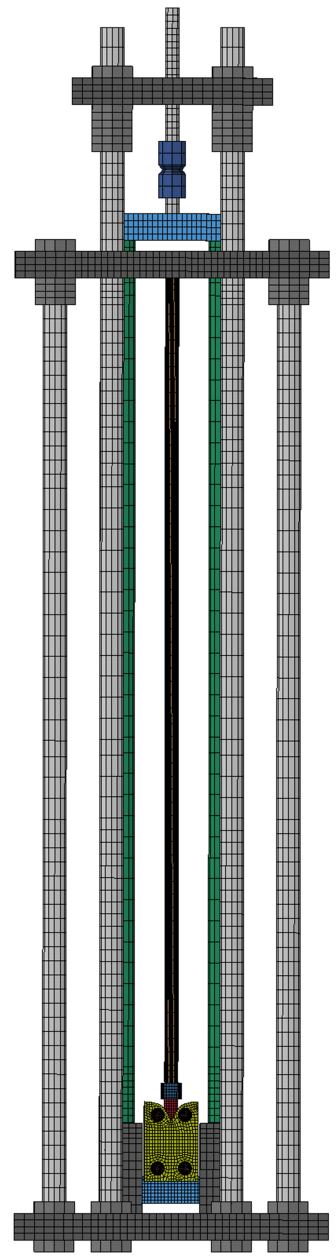

(b)

Figure 2. The refined impact testing system (M-SEFIM): (a) As-built; (b) FE model 


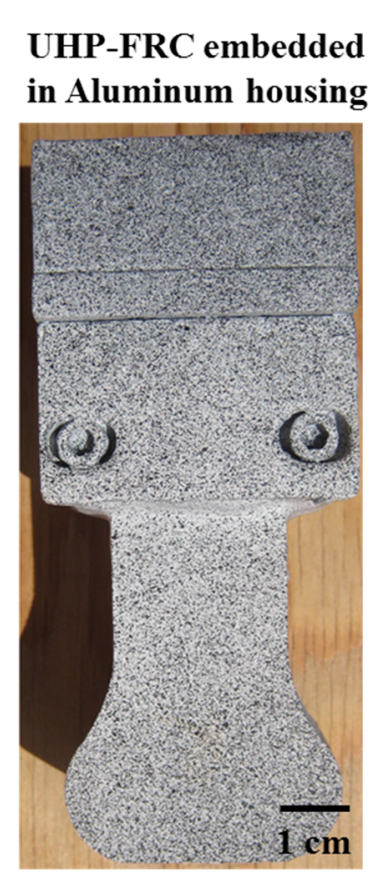

(a)

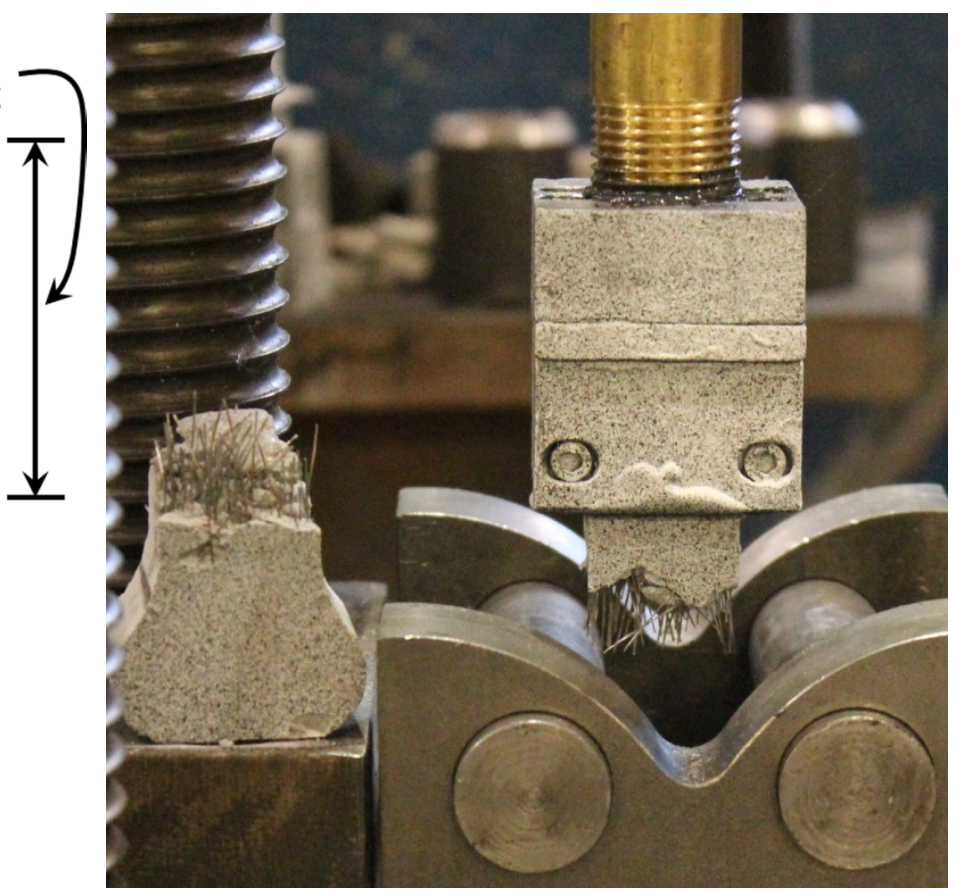

(b)

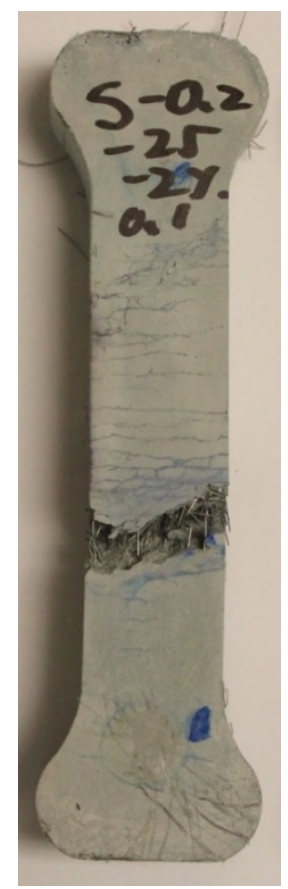

(c)

Figure 3. UHP-FRC specimens: (a) before testing for impact; (b) after testing for impact

[typical]; (c) used at lower strain rate testing

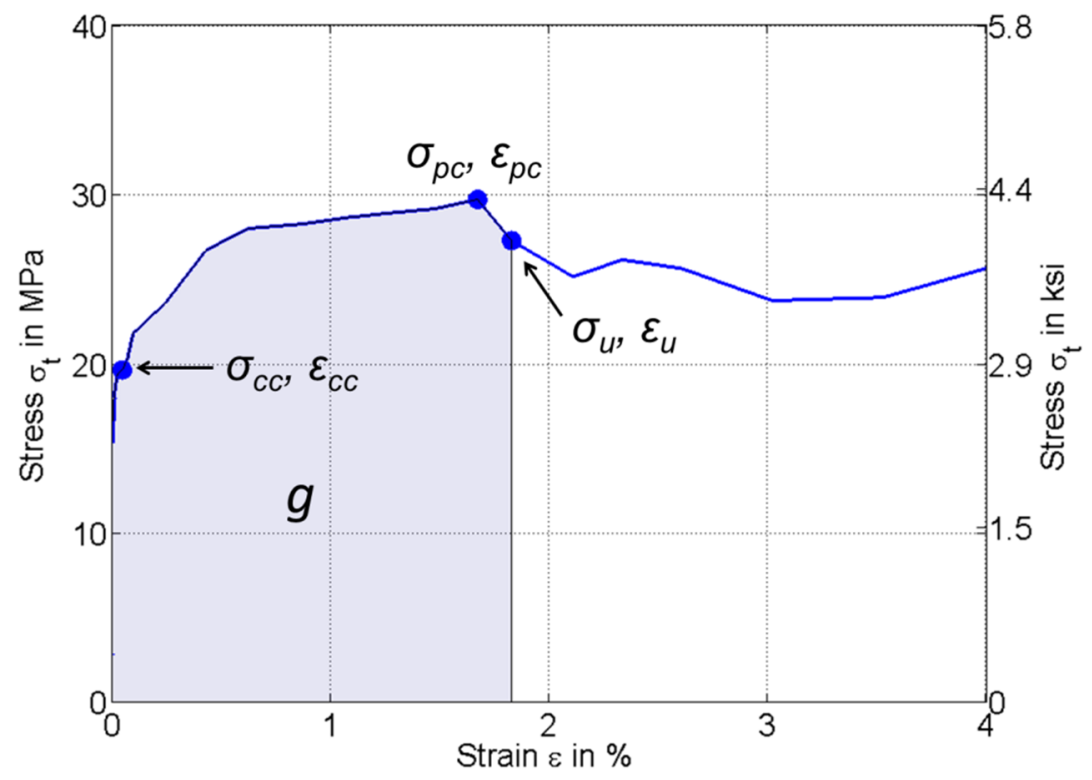

Figure 4. Typical interpretation of test results 

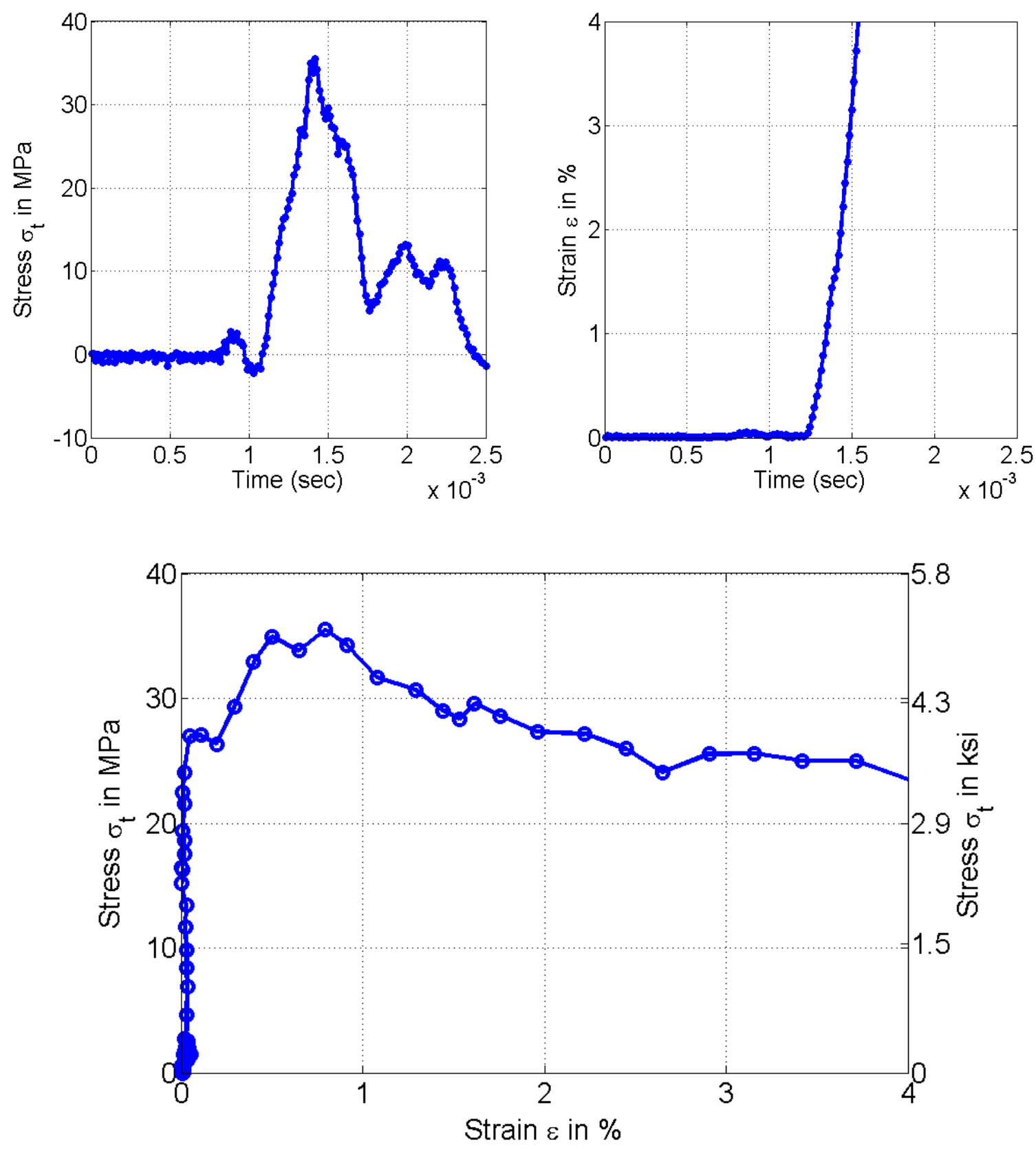

Figure 5. Example of data reading (T-0.3-25-1\%): (a) Stress reading; (b) Strain reading; (c) Stress-strain relation (Note: strain valid up to peak stress only.) 

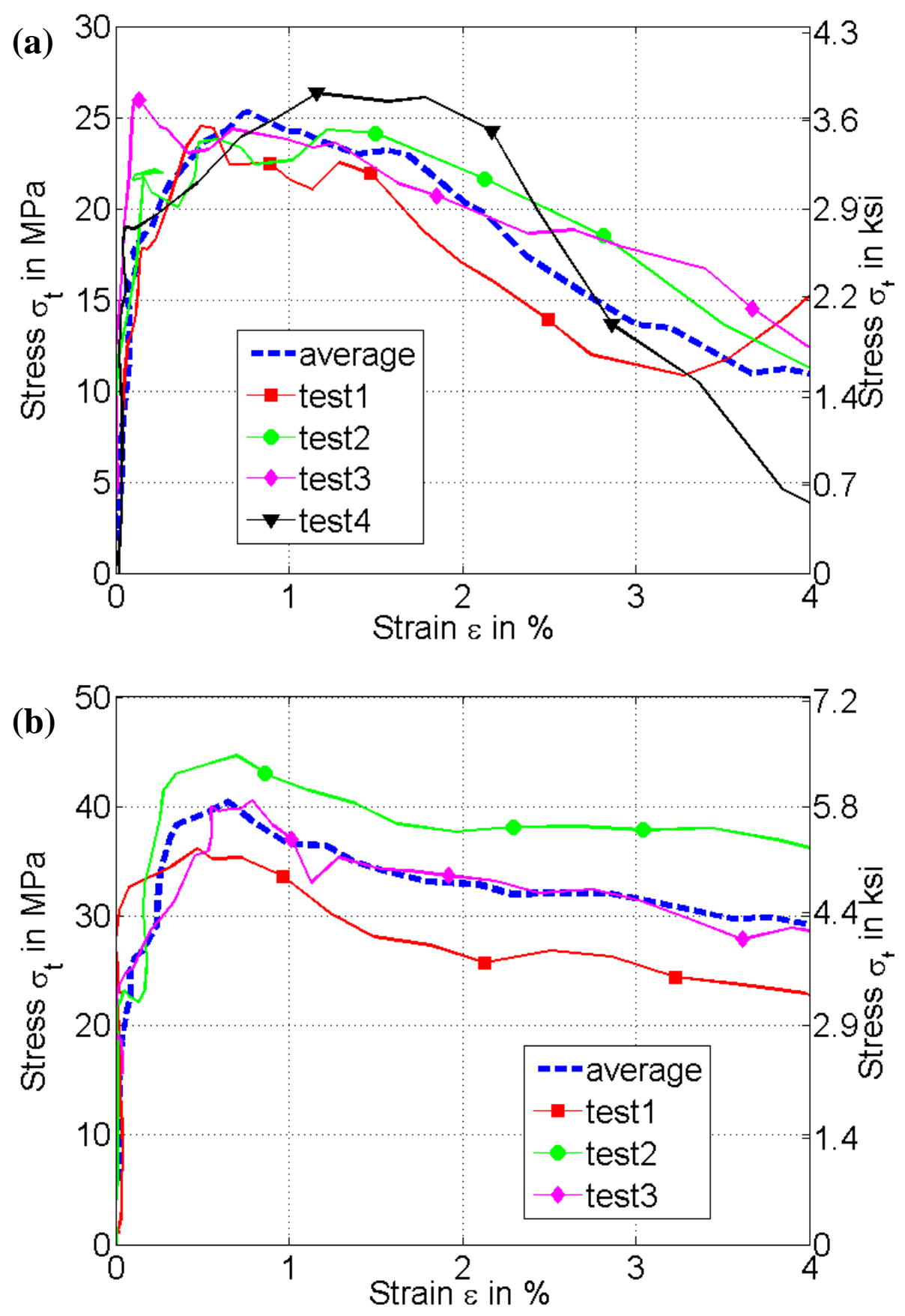

Figure 6. Comparisons between raw and averaged stress-strain data: (a) S-0.2-25-1\%; (b) S-0.425-3\% (Note: strain valid up to peak stress only.) 


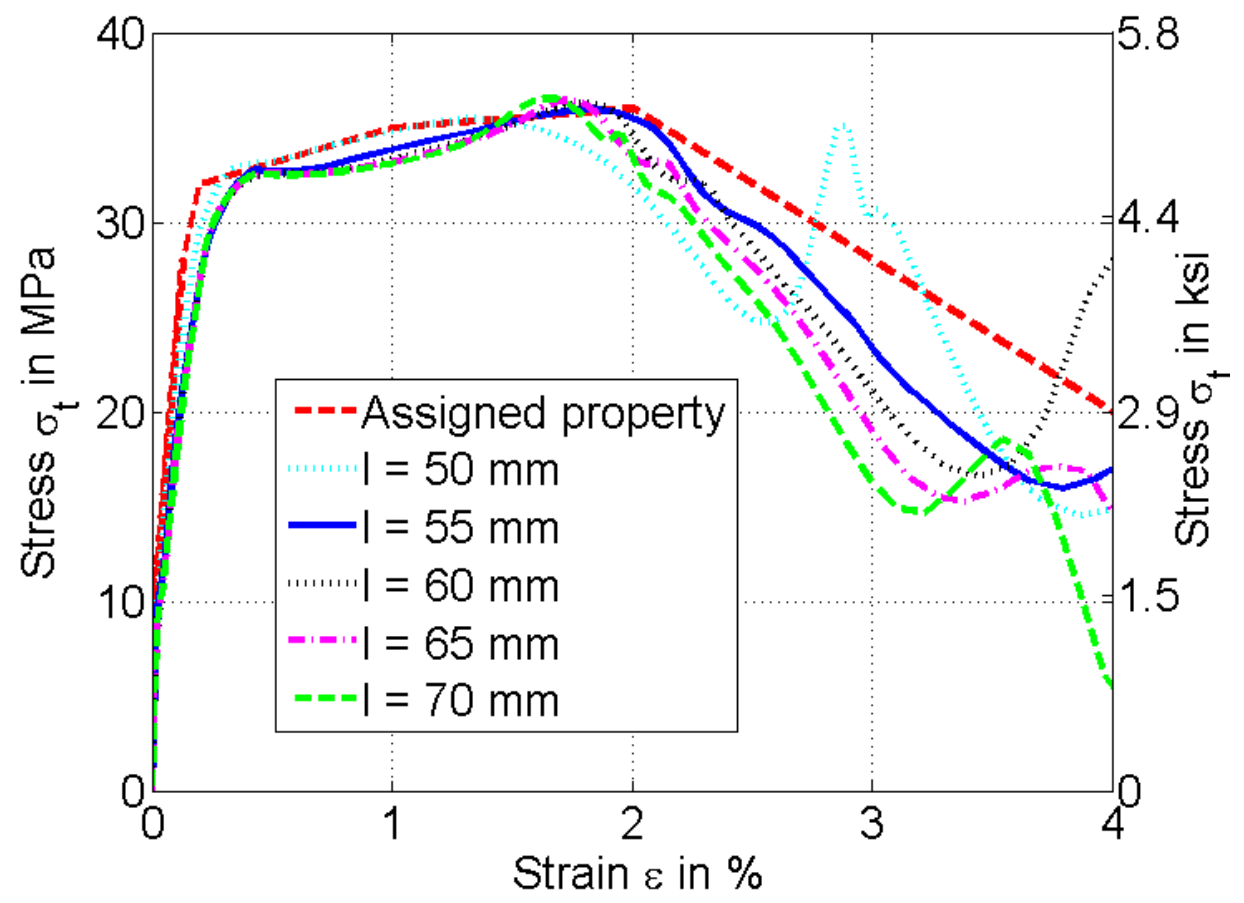

Figure 7. Stress-strain responses from the parametric study using simulations (Note: strain valid up to peak stress only.)

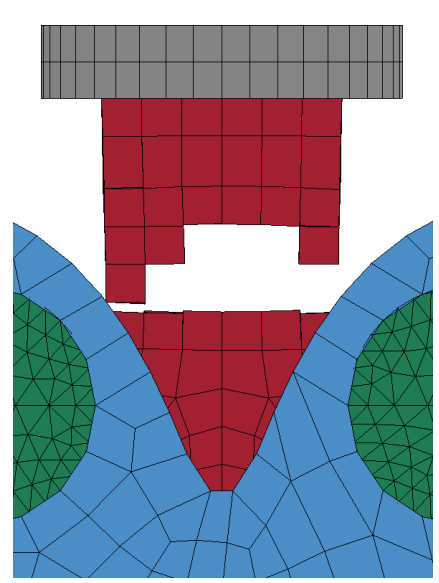

(a)

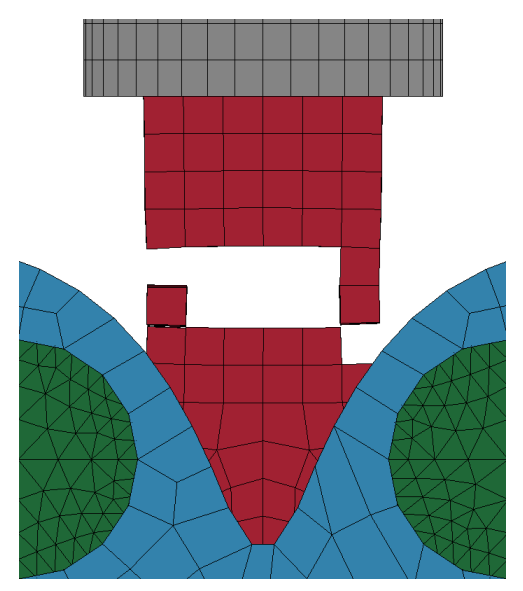

(b)

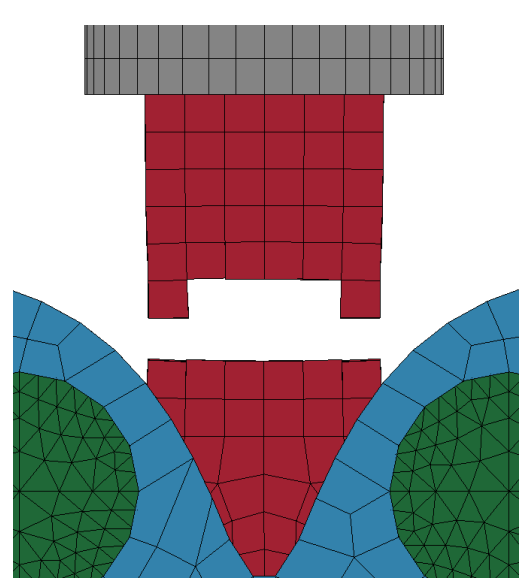

(c)

Figure 8. Examples of failure of UHP-FRC specimens in simulations: (a) $l=55 \mathrm{~mm}$; (b) $l=$ $60 \mathrm{~mm} ;$ (c) $l=65 \mathrm{~mm}$ 


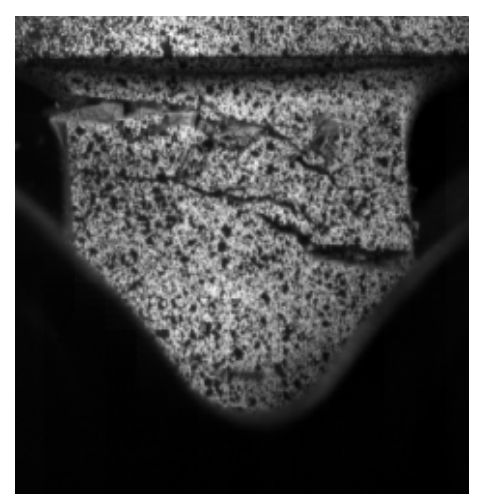

(a)

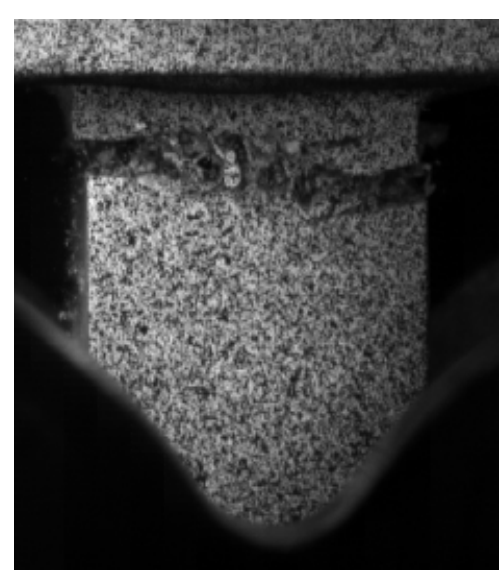

(b)

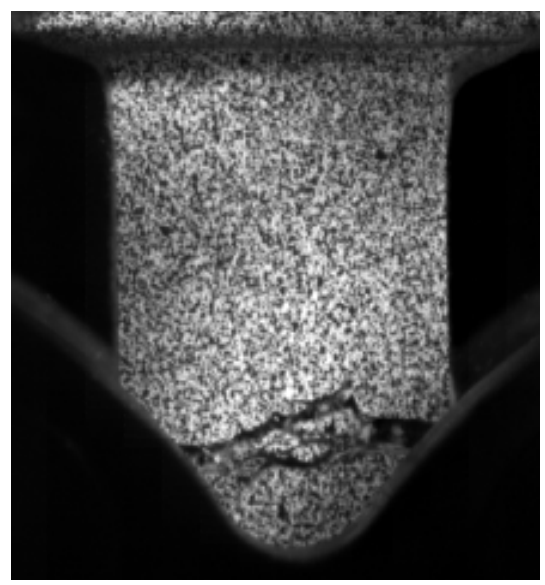

(c)

Figure 9. Examples of failure of UHP-FRC specimens in experiments: (a) $l=55 \mathrm{~mm}$; (b) $l=$ $60 \mathrm{~mm}$; (c) $l=65 \mathrm{~mm}$ (note that the darker lower part of the photos is part of the gripping fixture of the machine)

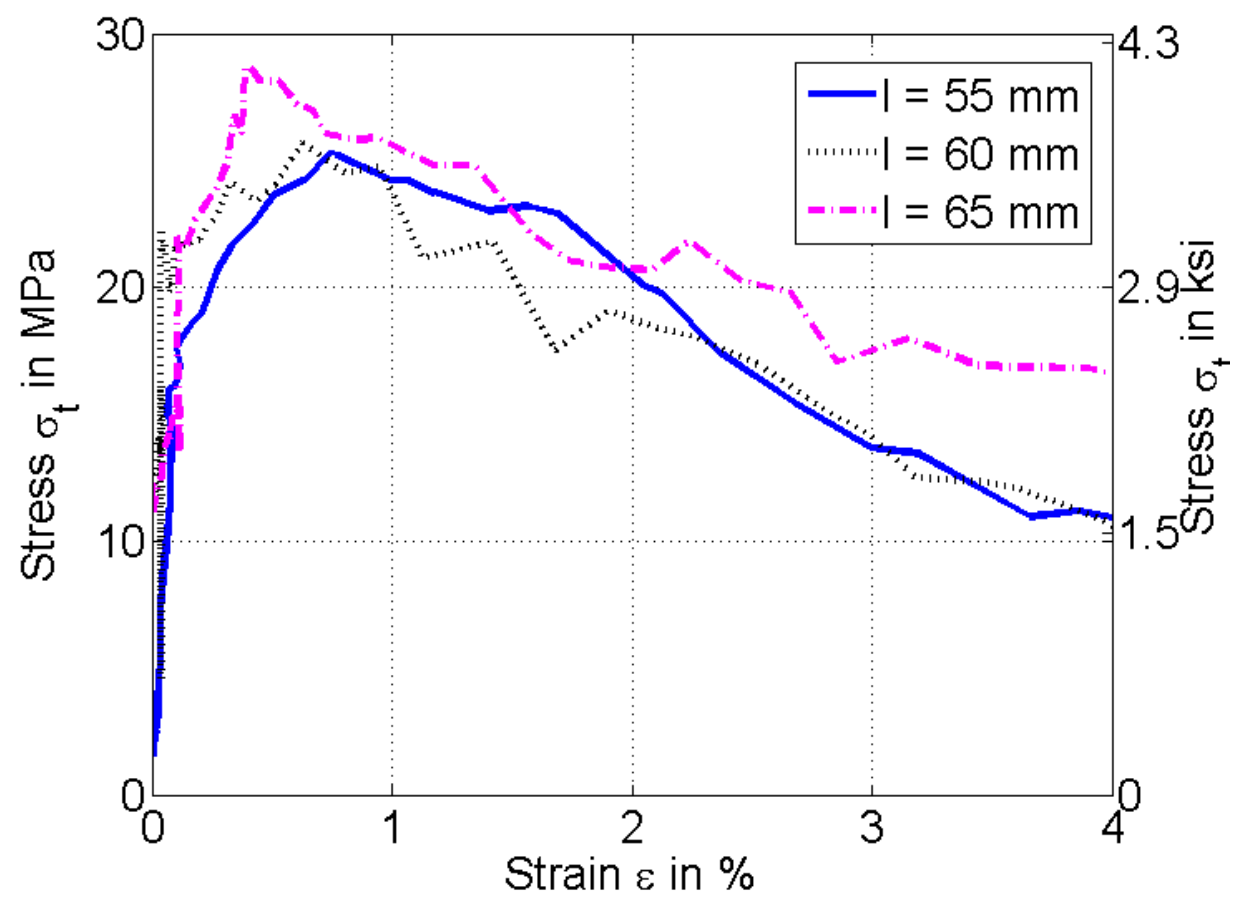

Figure 10. Stress-strain responses from the experimental study of specimen length 
(a)
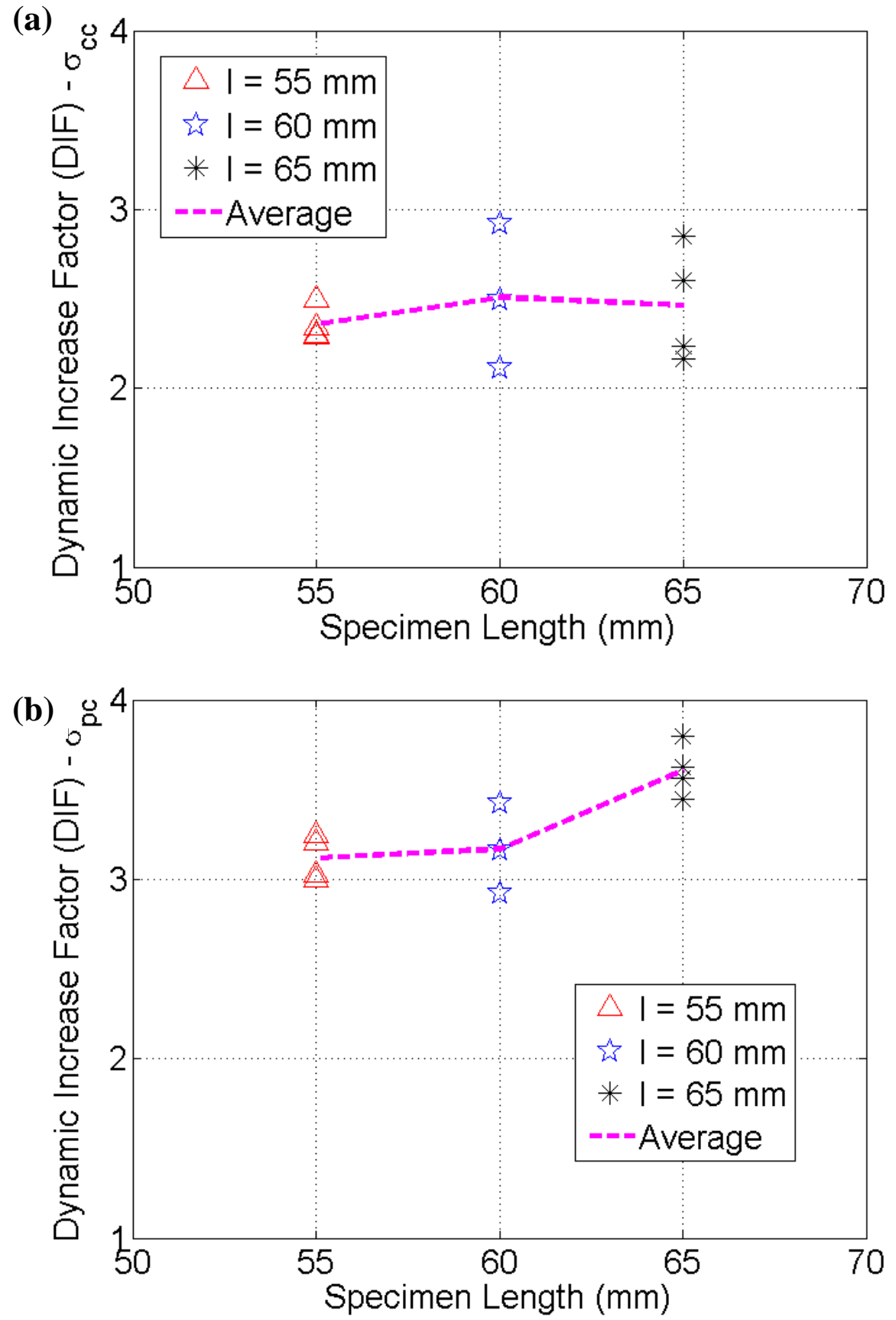

Figure 11. Experimentally obtained dynamic increase factor (DIF) of UHP-FRC specimens with different lengths: (a) First cracking strength; (b) Post cracking strength; (c) Energy absorption capacity; (d) Strain capacity 

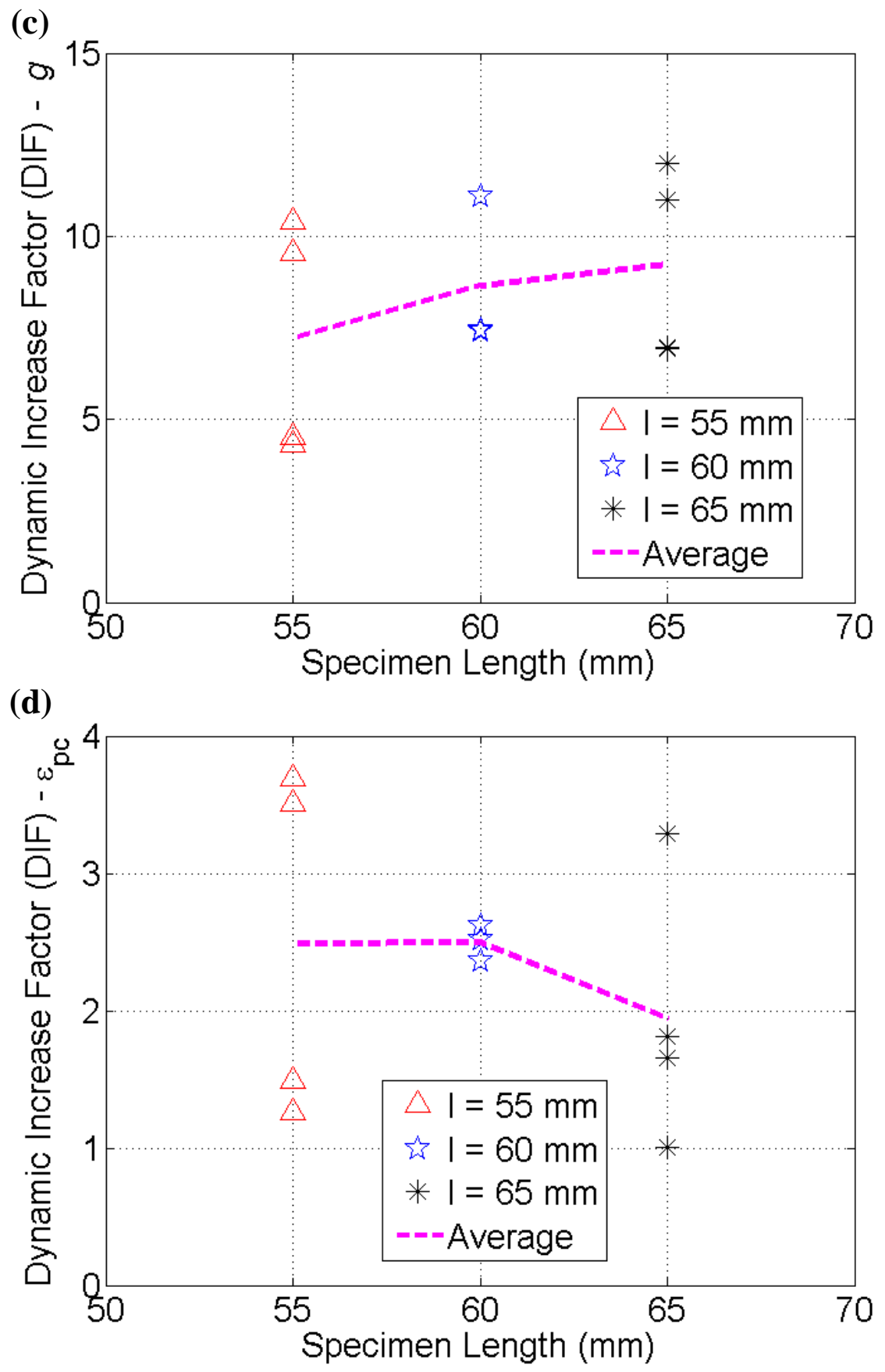

Figure 11. continued 


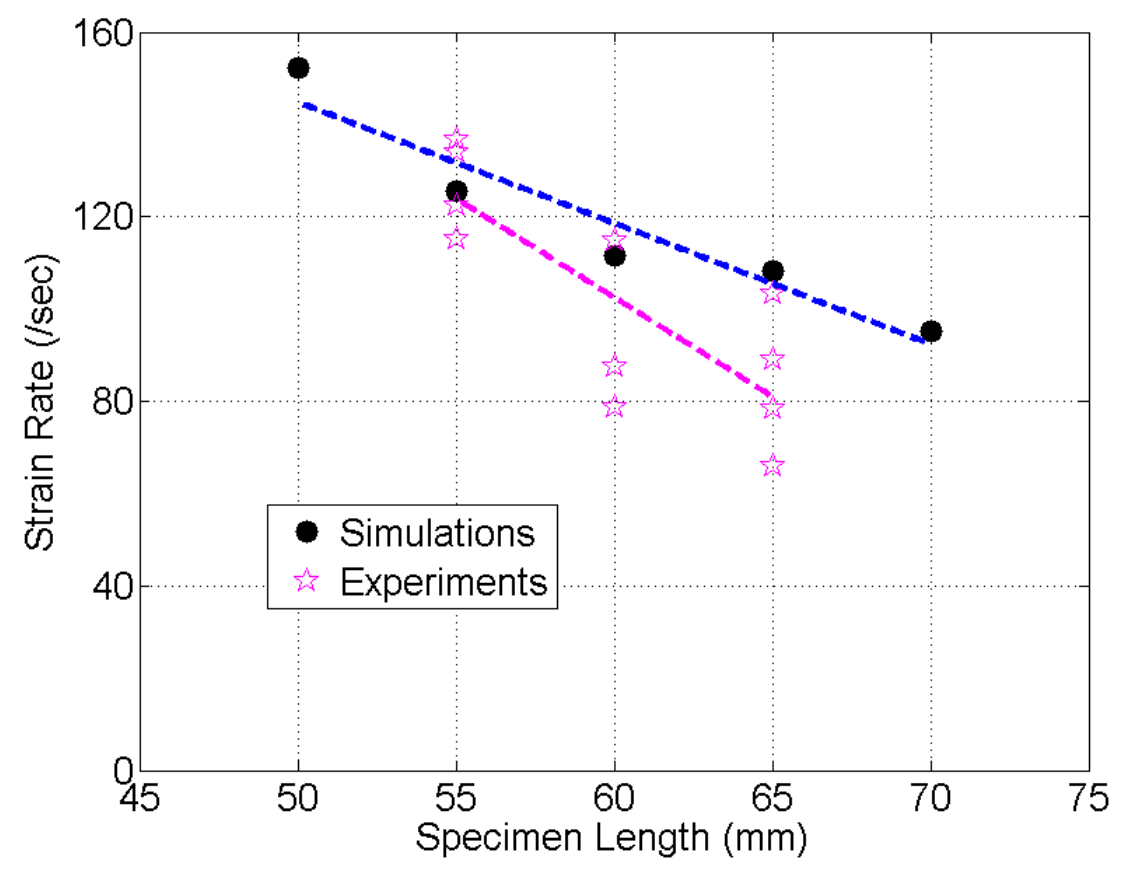

Figure 12. Strain rate versus specimen length 

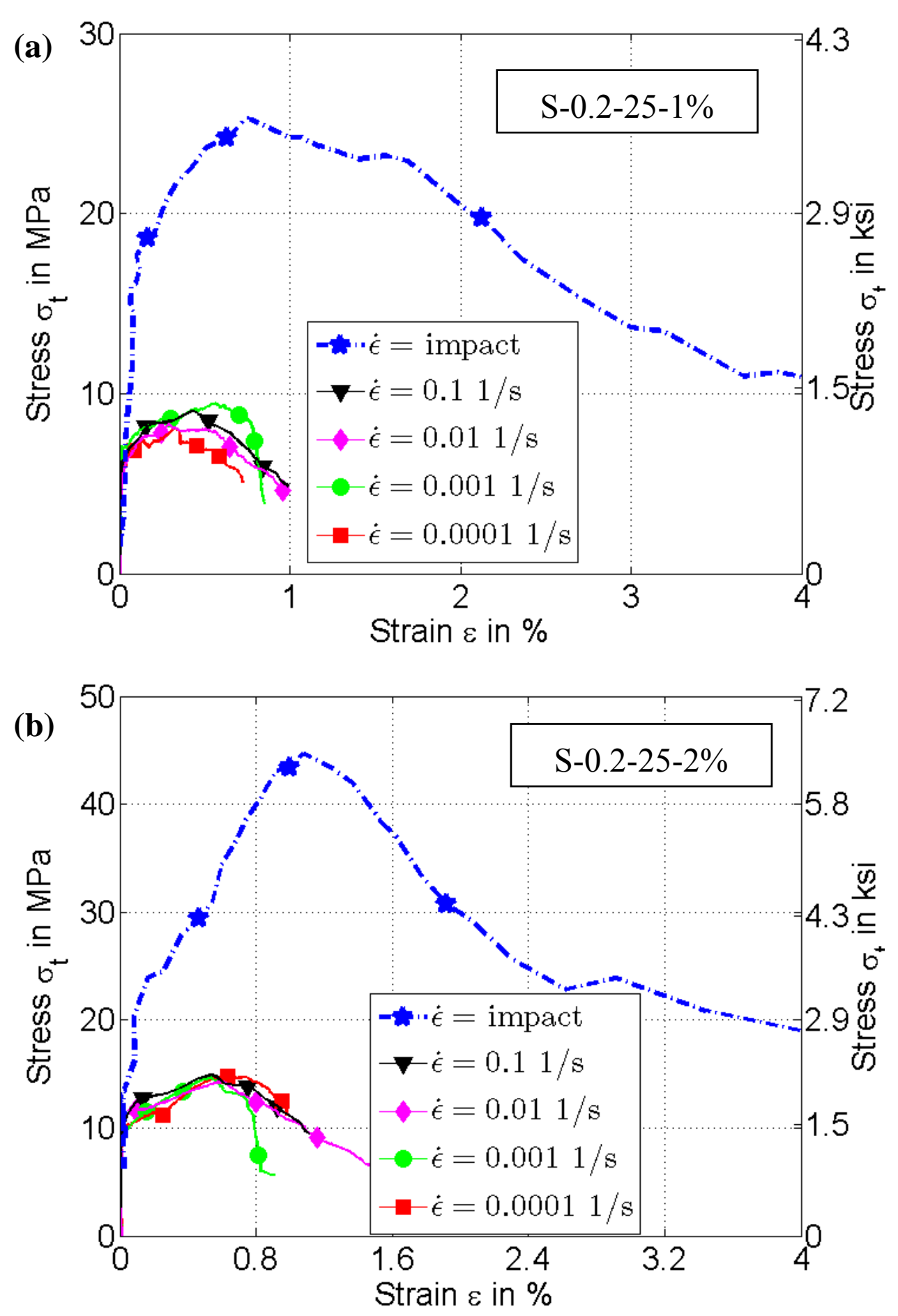

Figure 13. Rate effect on stress-strain response under tension of UHP-FRC using different fibers (Note: strain valid up to peak stress only.) 

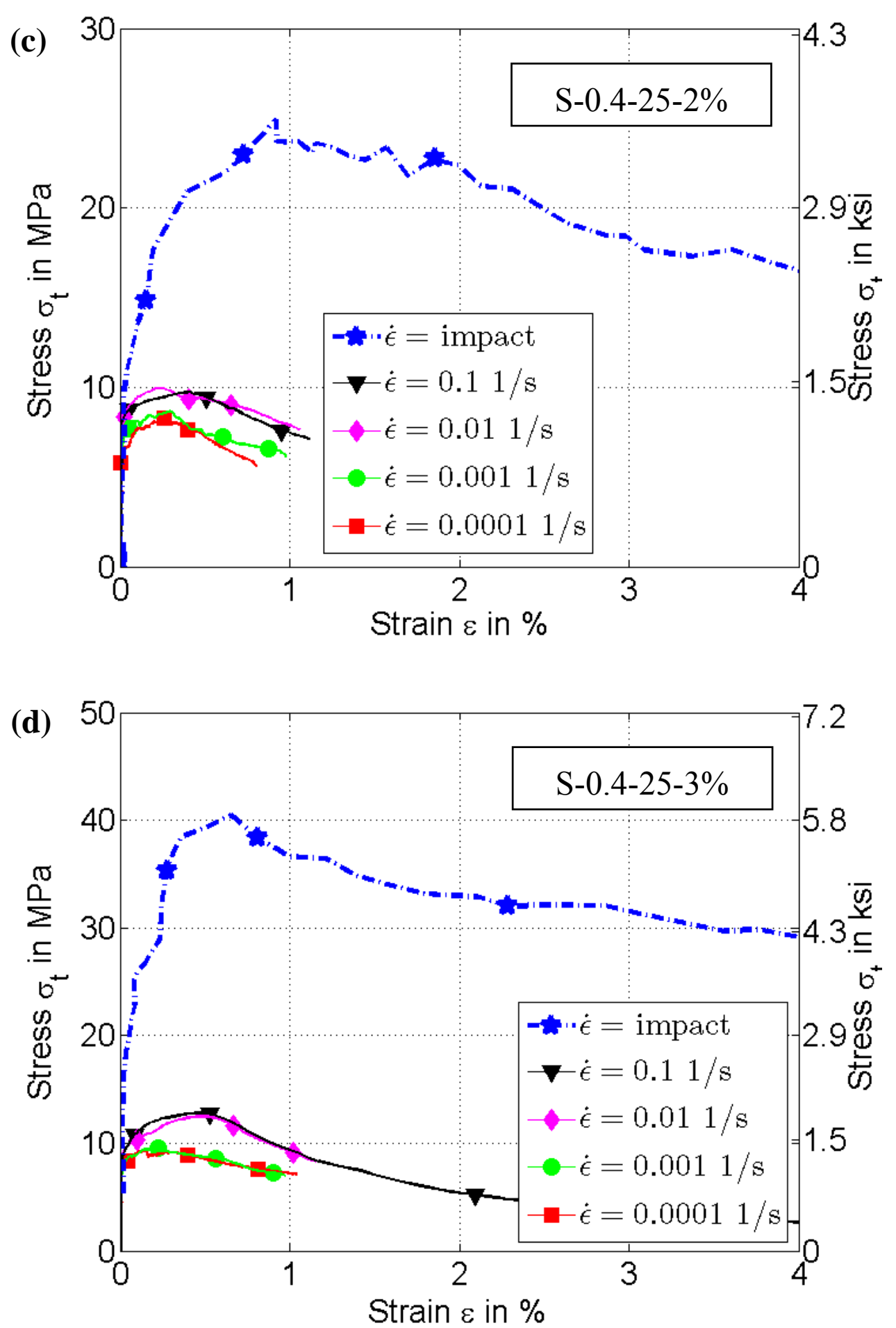

Figure 13. continued 

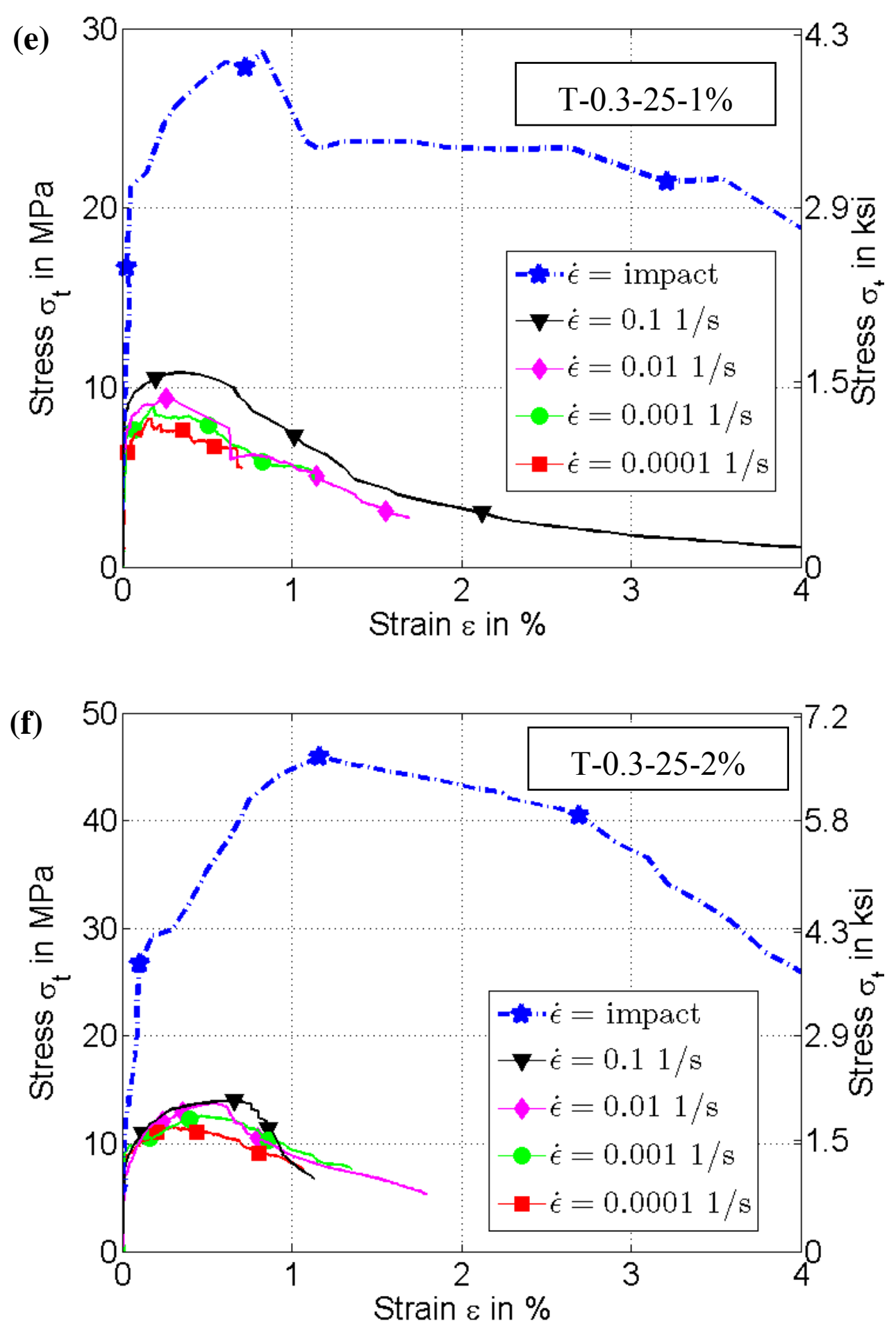

Figure 13. continued 


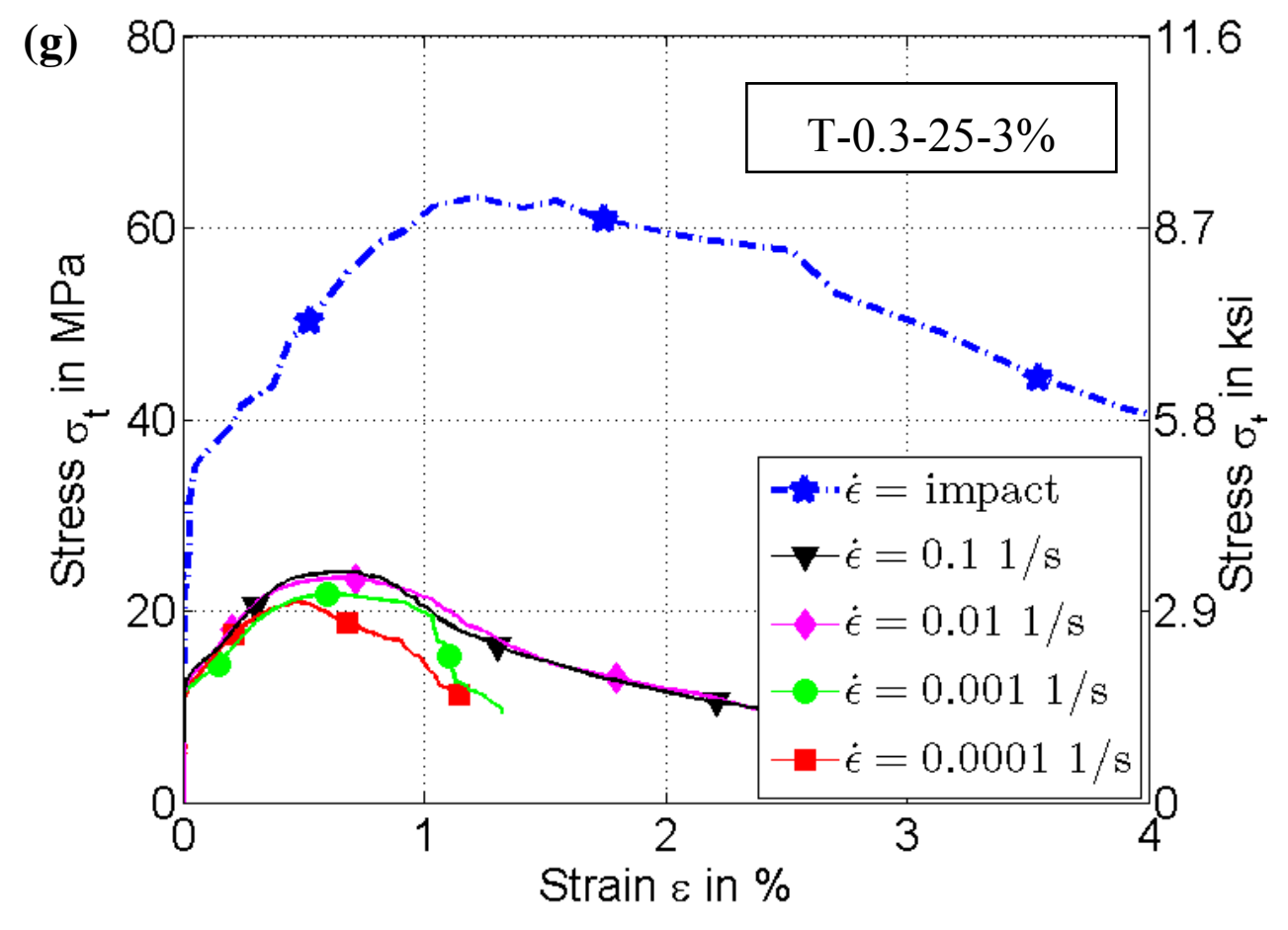

Figure 13. continued 

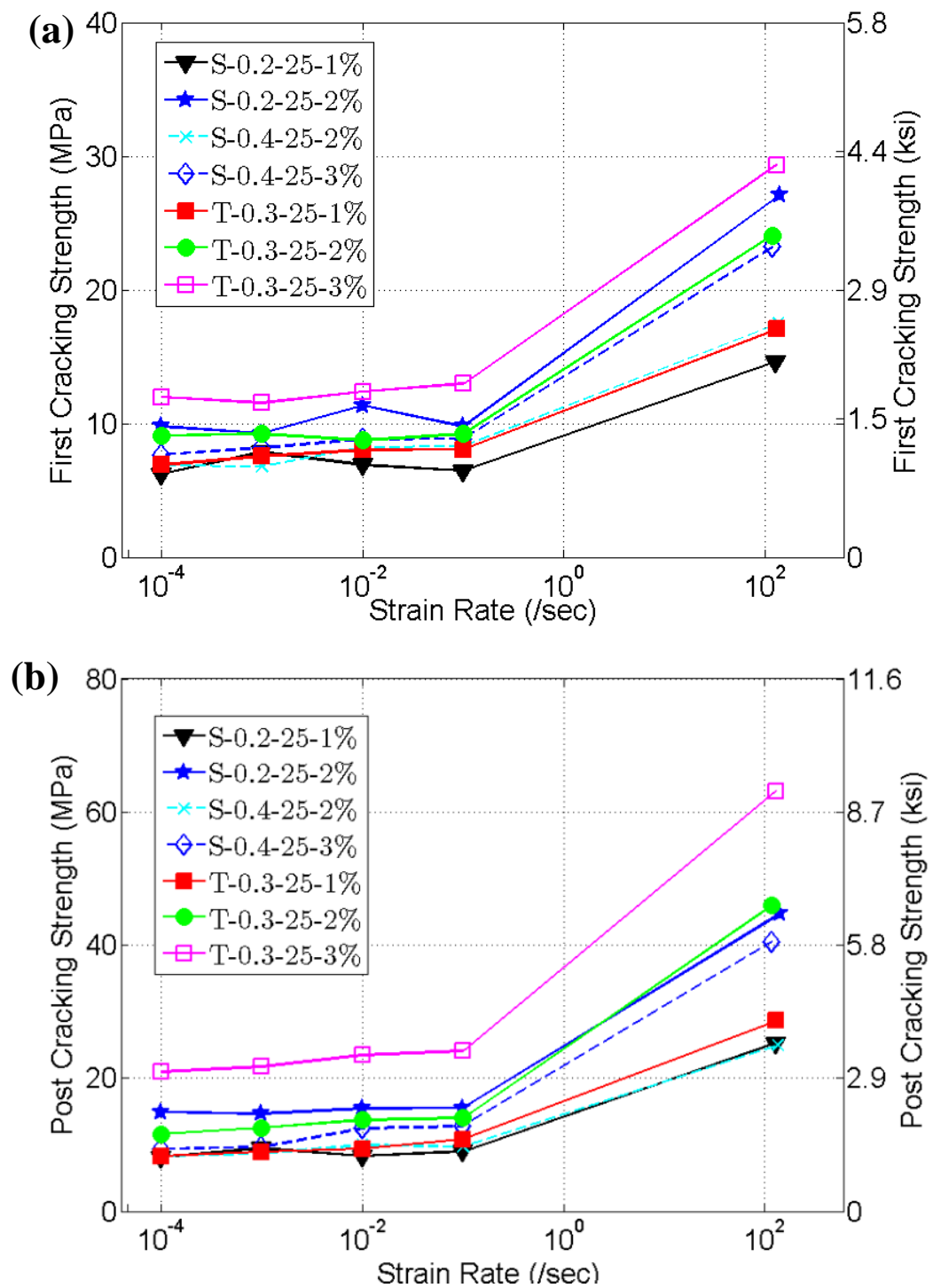

Figure 14. Rate effect of UHP-FRC using different fibers: (a) First cracking strength; (b) Post cracking strength; (c) Energy absorption capacity; (d) Strain capacity 

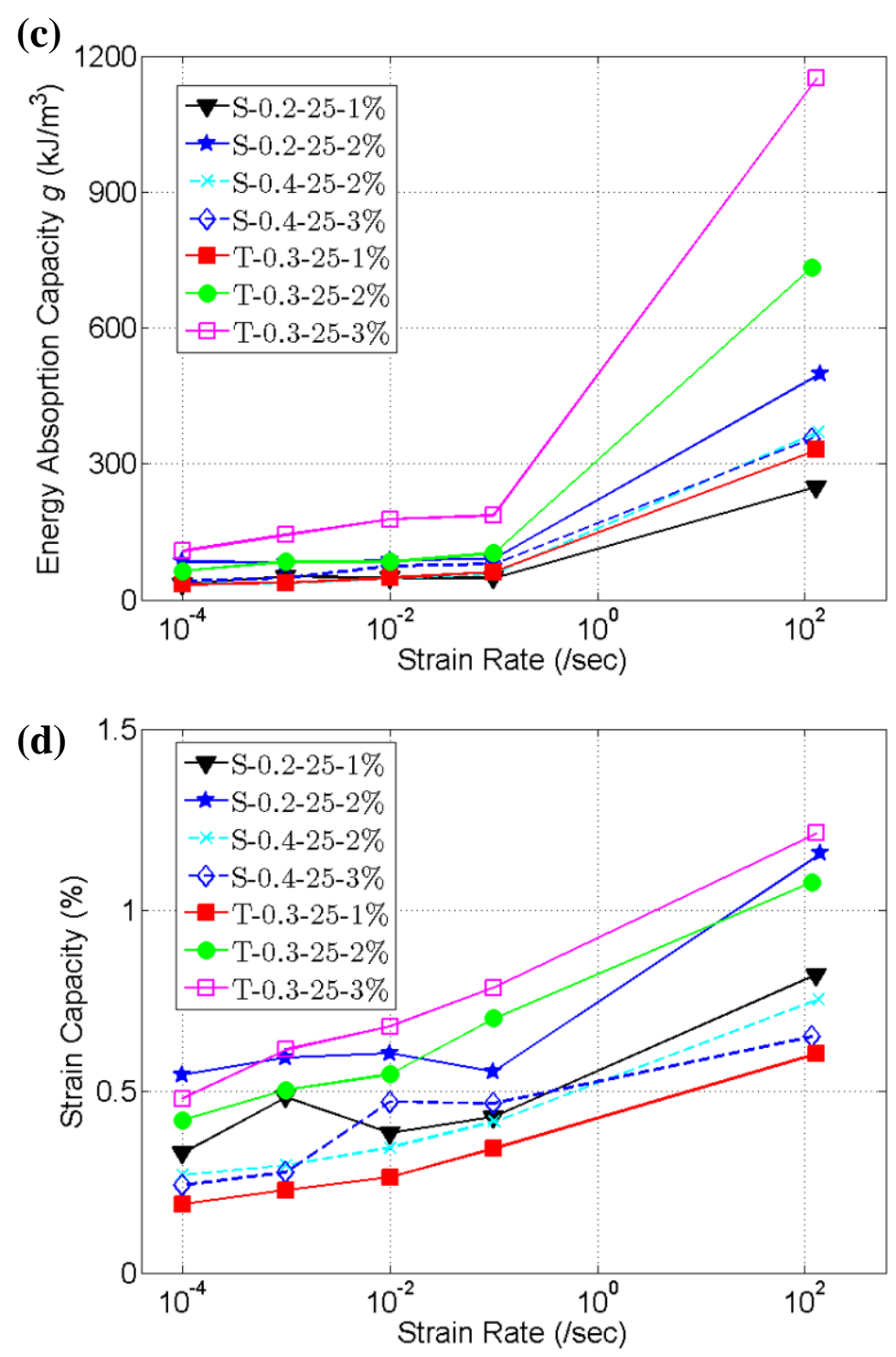

Figure 14. continued 


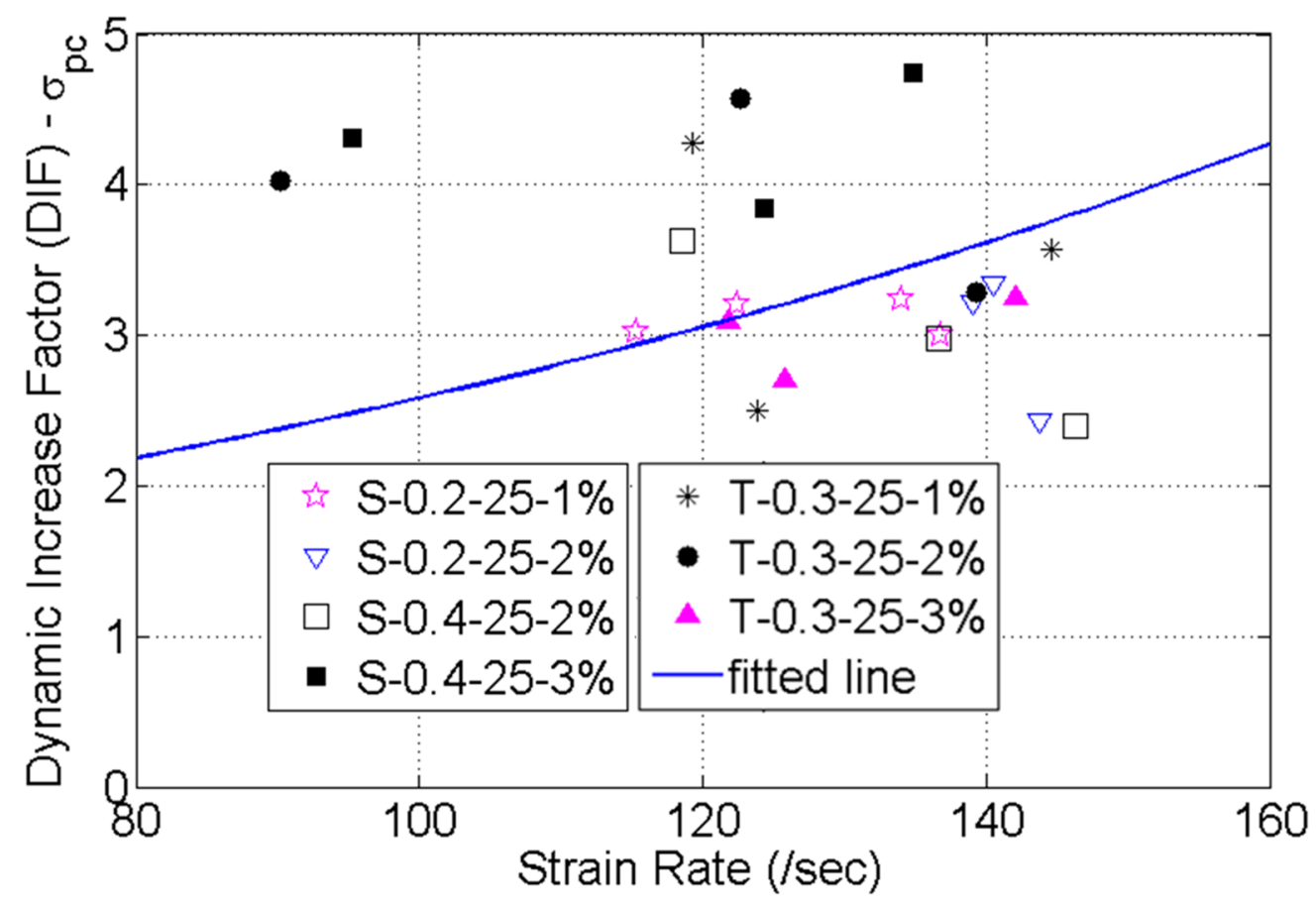

Figure 15. Dynamic increase factor (DIF) for post cracking strength (excluding lower strain rate data) 

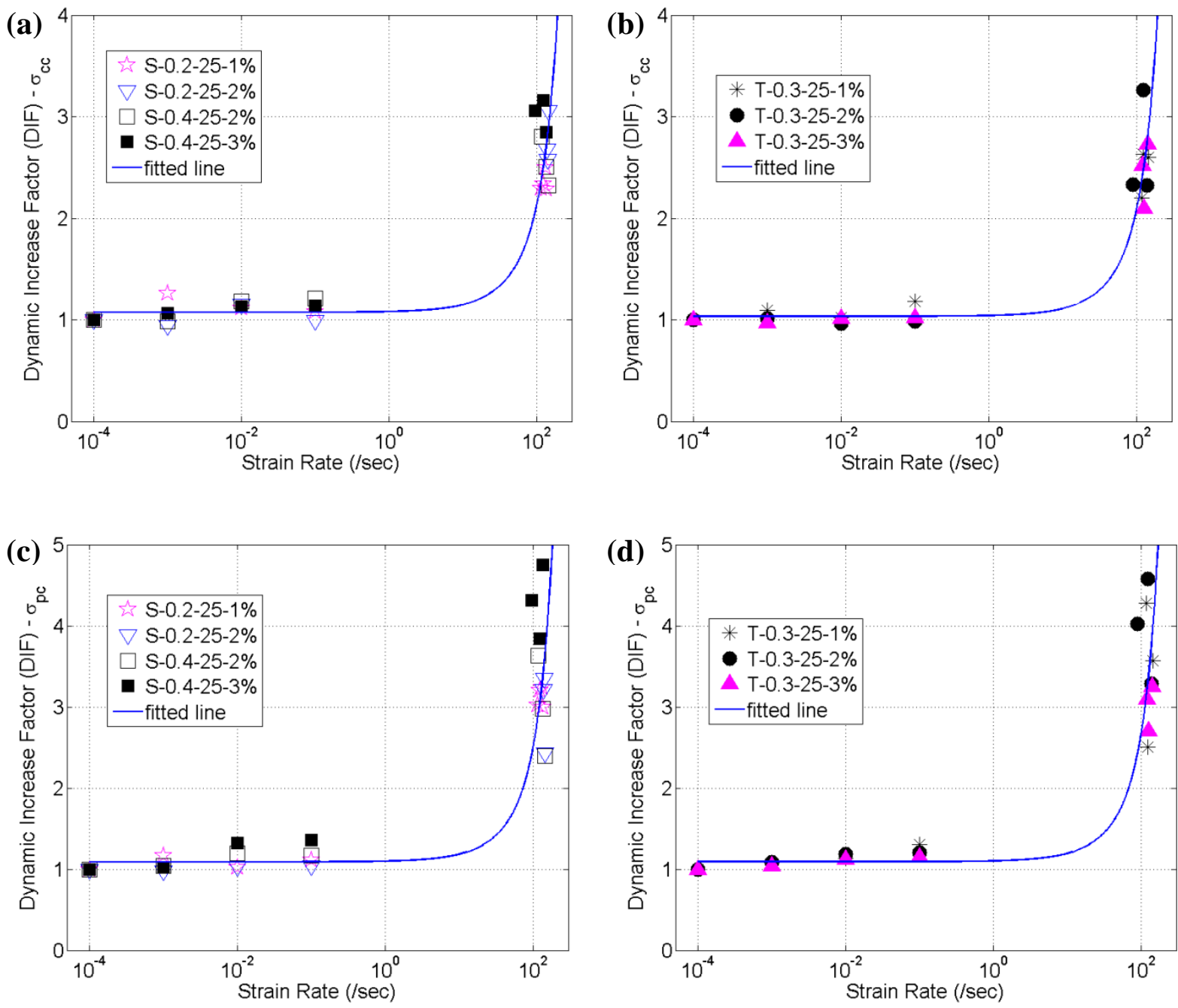

Figure 16. Dynamic increase factor (DIF) of UHP-FRC: (a) First cracking strength of smooth fiber; (b) First cracking strength of twisted fiber; (c) Post cracking strength of smooth fiber; (d) Post cracking strength of twisted fiber; (e) Energy absorption capacity of smooth fiber; (f) Energy absorption capacity of twisted fiber; (g) Strain capacity of smooth fiber; (h) Strain capacity of twisted fiber 

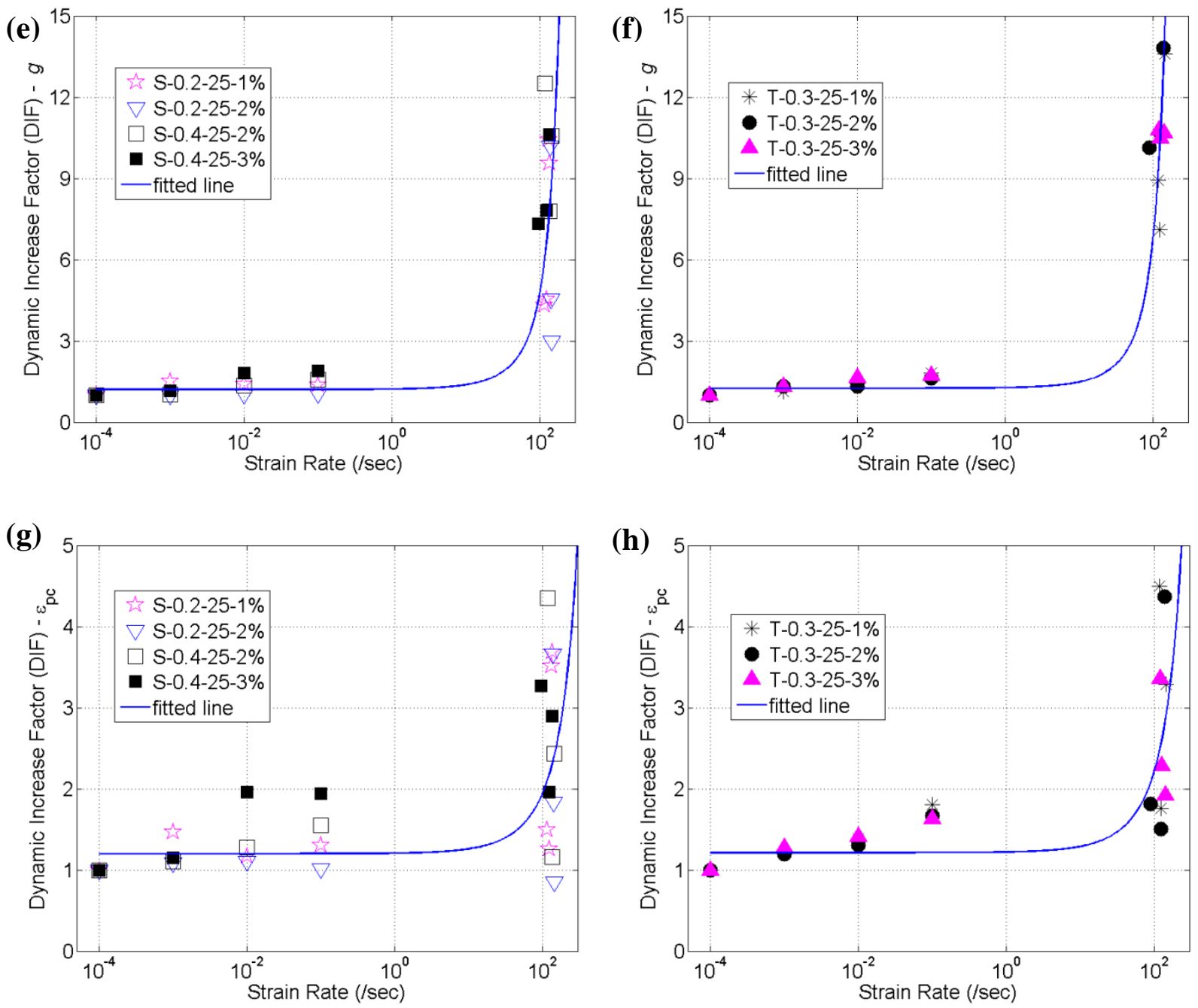

Figure 16. continued 

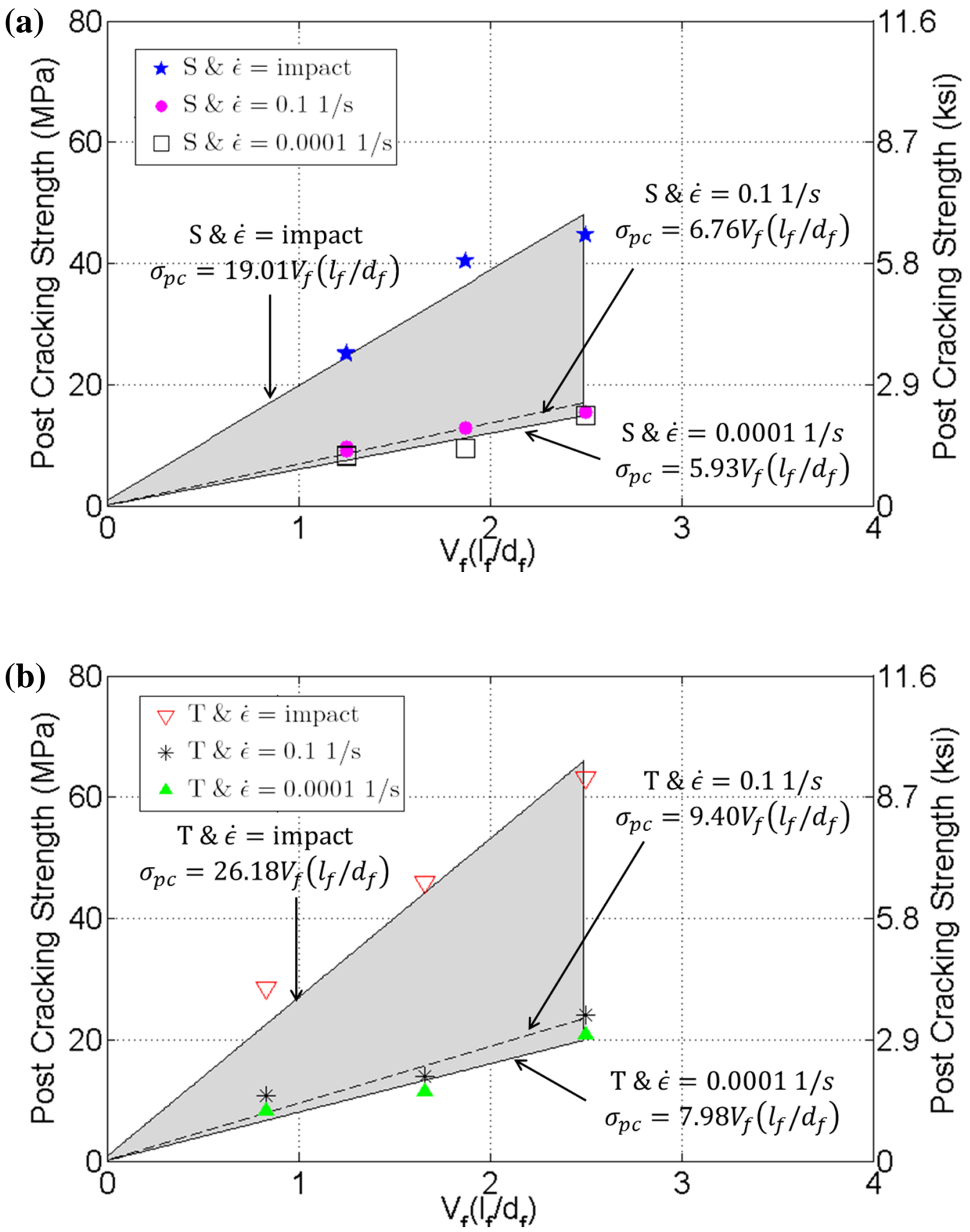

Figure 17. Effects of the fiber reinforcing index on post cracking strength: (a) Smooth fibers; (b) Twisted fibers 
(a)

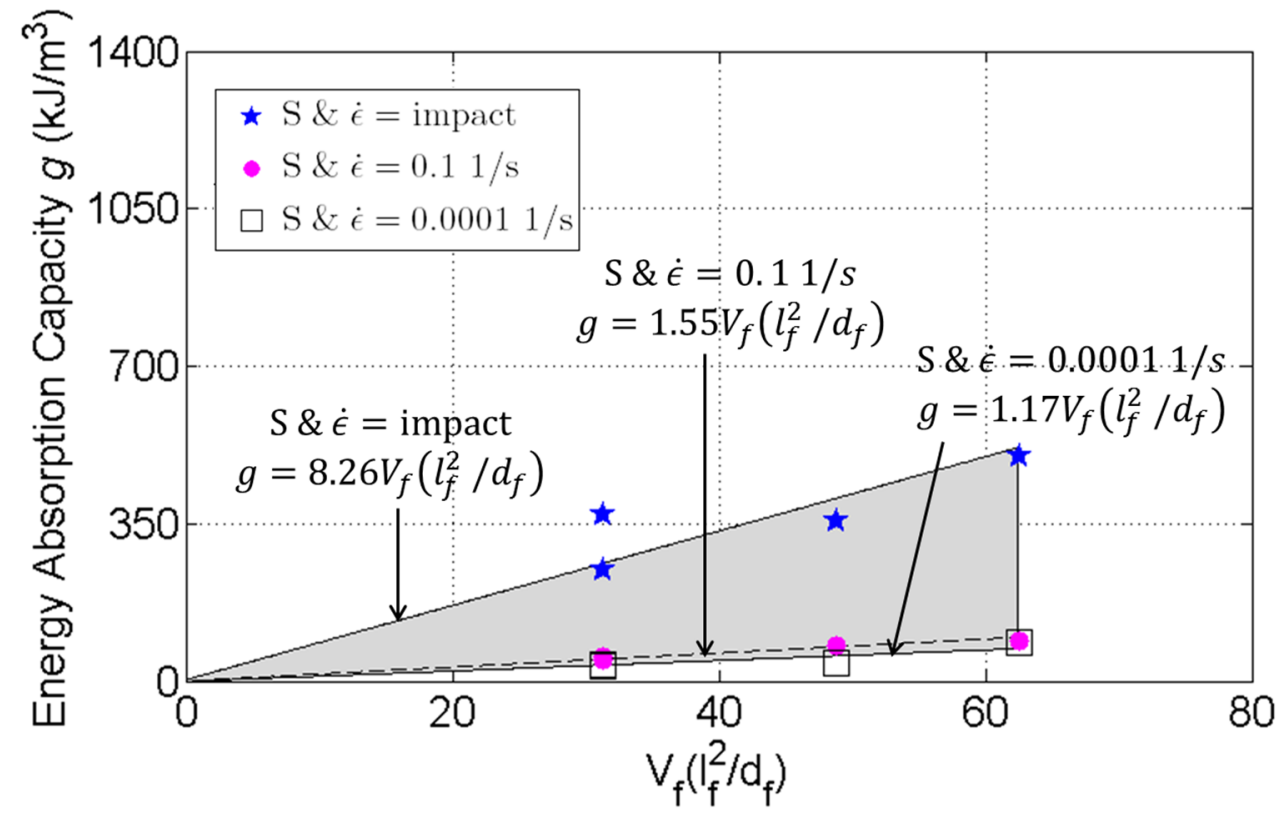

(b)

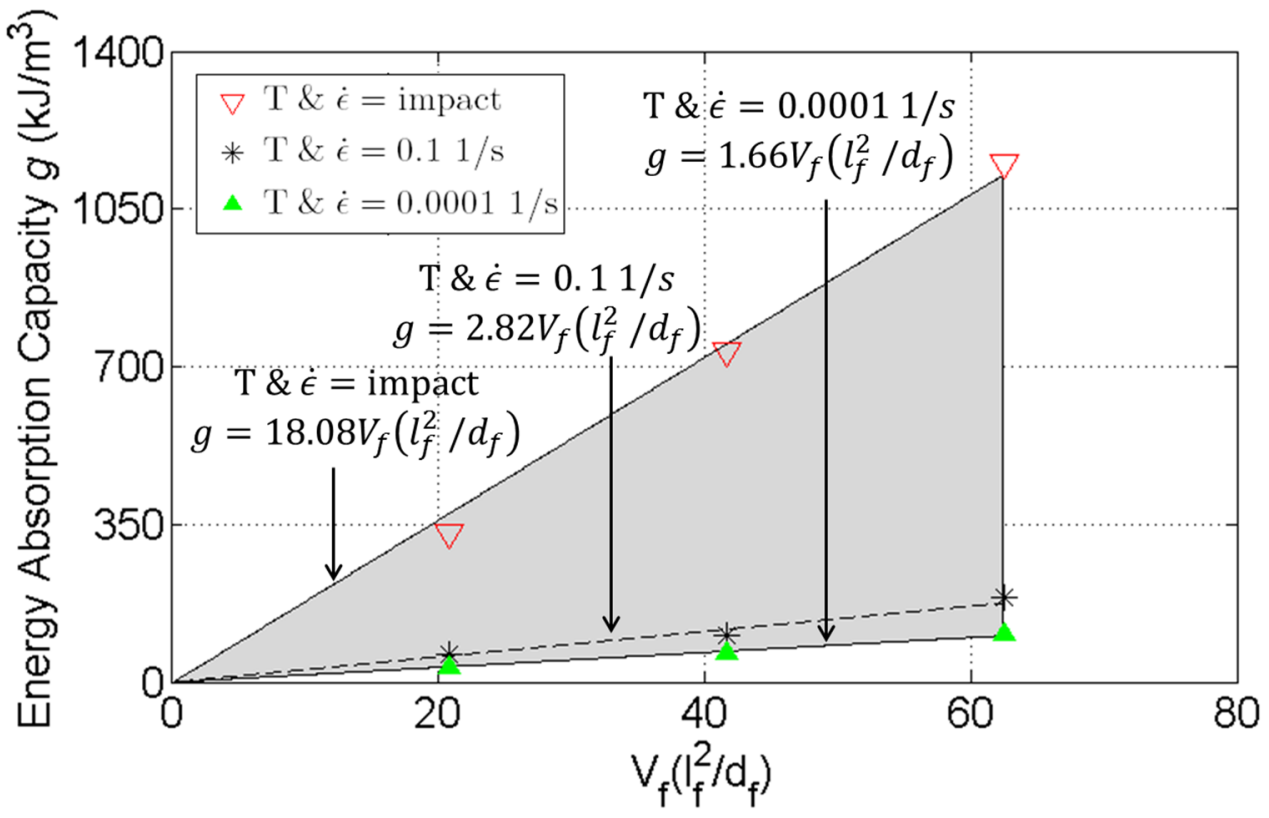

Figure 18. Effects of $V_{f}\left(l_{f}^{2} / d_{f}\right)$ on energy absorption capacity of UHP-FRC: (a) Smooth fibers;

(b) Twisted fibers 
Table 1. Example of mixtures proportions by weight [33]

\begin{tabular}{cc}
\hline Fiber Volume Fraction & $2 \%$ \\
\hline Cement & 1.00 \\
\hline Silica Fume & 0.25 \\
\hline Glass Powder & 0.25 \\
\hline Water & 0.22 \\
\hline Superplasticizer & 0.005 \\
\hline Sand $\mathrm{A}^{\dagger}$ & 0.26 \\
\hline Sand $\mathrm{B}^{\S}$ & 1.05
\end{tabular}

${ }^{\dagger}$ Maximum grain size $=0.2 \mathrm{~mm}(1 / 128 \mathrm{in}$.).

${ }^{\S}$ Maximum grain size $=0.8 \mathrm{~mm}(1 / 32 \mathrm{in}$.).

Table 2. Properties of steel fibers used in this study

\begin{tabular}{cccccc}
\hline Notation & Form & $d_{f}(\mathrm{~mm})$ & $l_{f}(\mathrm{~mm})$ & $l_{f} / d_{f}$ & $\begin{array}{c}\text { Tensile strength } \\
\text { MPa }(\mathrm{ksi})\end{array}$ \\
\hline T-0.3-25 & Twisted* & 0.3 & 25 & 83 & $2670(387)^{\dagger}$ \\
\hline S-0.2-25 & Straight & 0.2 & 25 & 125 & $2860(415)$ \\
\hline S-0.4-25 & Straight & 0.4 & 25 & 62.5 & $1850(268)$
\end{tabular}

\& Values under quasi-static loading

* Manufactured out of round wire stock of diameter $d f$.

$\dagger$ Tensile strength of fiber after twisting 
Table 3. Summary of impact test results

\begin{tabular}{|c|c|c|c|c|c|c|c|c|c|c|c|}
\hline \multirow[t]{2}{*}{$\begin{array}{c}\text { Test } \\
\text { series }\end{array}$} & \multirow[t]{2}{*}{$\begin{array}{l}\text { Specimen } \\
\text { length }(\ell) \\
(\mathrm{mm})\end{array}$} & & \multirow[t]{2}{*}{$\begin{array}{l}\text { Strain } \\
\text { rate }\end{array}$} & \multicolumn{2}{|c|}{$\begin{array}{l}\text { First cracking } \\
\text { strength } \\
\left(\sigma_{\mathrm{cc}}\right)\end{array}$} & \multicolumn{2}{|c|}{$\begin{array}{l}\text { Post cracking } \\
\text { strength } \\
\left(\sigma_{\mathrm{pc}}\right)\end{array}$} & \multicolumn{2}{|c|}{$\begin{array}{c}\text { Energy } \\
\text { absorption } \\
\text { capacity } \\
(g)\end{array}$} & \multicolumn{2}{|c|}{$\begin{array}{l}\text { Strain } \\
\text { capacity } \\
\left(\varepsilon_{p c}\right)\end{array}$} \\
\hline & & & & $\mathrm{MPa}$ & DIF & $\mathrm{MPa}$ & DIF & $\mathrm{kJ} / \mathrm{m}^{3}$ & DIF & $\%$ & DIF \\
\hline \multirow{14}{*}{$\begin{array}{l}\text { S-0.2- } \\
25-1 \%\end{array}$} & \multirow{5}{*}{55} & & 115.3 & 14.3 & 2.3 & 24.5 & 3.0 & 148.9 & 4.3 & 0.493 & 1.5 \\
\hline & & & 122.4 & 14.5 & 2.3 & 26.0 & 3.2 & 156.5 & 4.5 & 0.417 & 1.3 \\
\hline & & & 133.9 & 15.5 & 2.5 & 26.3 & 3.2 & 359.8 & 10.4 & 1.161 & 3.5 \\
\hline & & & 136.8 & 14.2 & 2.3 & 24.3 & 3.0 & 329.7 & 9.5 & 1.219 & 3.7 \\
\hline & & Average & 127.1 & 14.6 & 2.4 & 25.3 & 3.1 & 248.7 & 7.2 & 0.823 & 2.5 \\
\hline & \multirow{4}{*}{60} & \multirow[b]{4}{*}{ Average } & 78.87 & 18.1 & 2.9 & 23.7 & 2.9 & 382.5 & 11.1 & 0.865 & 2.6 \\
\hline & & & 87.54 & 15.6 & 2.5 & 27.7 & 3.4 & 255.8 & 7.4 & 0.832 & 2.5 \\
\hline & & & 114.8 & 13.2 & 2.1 & 25.6 & 3.2 & 257.5 & 7.5 & 0.779 & 2.4 \\
\hline & & & 93.72 & 15.6 & 2.5 & 25.7 & 3.2 & 298.6 & 8.6 & 0.826 & 2.5 \\
\hline & \multirow{5}{*}{65} & & 65.98 & 13.5 & 2.2 & 29.4 & 3.6 & 379.4 & 11.0 & 0.600 & 1.8 \\
\hline & & & 78.42 & 13.9 & 2.2 & 27.9 & 3.4 & 240.8 & 7.0 & 0.546 & 1.7 \\
\hline & & & 89.03 & 17.7 & 2.9 & 28.9 & 3.6 & 239.5 & 6.9 & 0.332 & 1.0 \\
\hline & & & 103.3 & 16.2 & 2.6 & 30.8 & 3.8 & 414.0 & 12.0 & 1.087 & 3.3 \\
\hline & & Average & 84.18 & 15.3 & 2.5 & 29.3 & 3.6 & 318.4 & 9.2 & 0.641 & 1.9 \\
\hline \multirow{4}{*}{$\begin{array}{l}\text { S-0.2- } \\
25-2 \%\end{array}$} & \multirow{4}{*}{55} & & 139.1 & 26.2 & 2.7 & 47.9 & 3.2 & 860.3 & 10.2 & 1.999 & 3.7 \\
\hline & & & 140.6 & 25.2 & 2.6 & 49.9 & 3.3 & 383.4 & 4.5 & 1.002 & 1.8 \\
\hline & & & 143.8 & 29.9 & 3.1 & 36.2 & 2.4 & 252.4 & 3.0 & 0.466 & 0.9 \\
\hline & & Average & 141.1 & 27.1 & 2.8 & 44.7 & 3.0 & 498.7 & 5.9 & 1.156 & 2.1 \\
\hline \multirow{4}{*}{$\begin{array}{l}\text { S- } 0.4- \\
25-2 \%\end{array}$} & \multirow{4}{*}{55} & & 118.6 & 19.3 & 2.8 & 30.2 & 3.6 & 448.9 & 12.5 & 1.172 & 4.3 \\
\hline & & & 136.6 & 17.2 & 2.5 & 24.7 & 3.0 & 280.0 & 7.8 & 0.435 & 1.6 \\
\hline & & & 146.3 & 16.0 & 2.3 & 19.9 & 2.4 & 379.7 & 10.6 & 0.656 & 2.4 \\
\hline & & Average & 133.8 & 17.5 & 2.5 & 25.0 & 3.0 & 369.5 & 10.3 & 0.754 & 2.8 \\
\hline \multirow{4}{*}{$\begin{array}{l}\text { S-0.4- } \\
25-3 \%\end{array}$} & \multirow{4}{*}{55} & & 95.22 & 23.5 & 3.1 & 40.6 & 4.3 & 302.5 & 7.3 & 0.786 & 3.3 \\
\hline & & & 124.3 & 24.2 & 3.2 & 36.2 & 3.8 & 323.8 & 7.8 & 0.471 & 2.0 \\
\hline & & & 134.8 & 21.9 & 2.9 & 44.7 & 4.7 & 439.5 & 10.6 & 0.697 & 2.9 \\
\hline & & Average & 118.1 & 23.2 & 3.0 & 40.5 & 4.3 & 355.3 & 8.6 & 0.651 & 2.7 \\
\hline \multirow{4}{*}{$\begin{array}{l}\mathrm{T}-0.3- \\
25-1 \%\end{array}$} & \multirow{4}{*}{55} & & 119.3 & 15.2 & 2.2 & 35.5 & 4.3 & 298.8 & 8.9 & 0.854 & 4.5 \\
\hline & & & 123.9 & 18.1 & 2.6 & 20.8 & 2.5 & 238.2 & 7.1 & 0.335 & 1.8 \\
\hline & & & 144.6 & 18.0 & 2.6 & 29.7 & 3.6 & 455.1 & 13.6 & 0.624 & 3.3 \\
\hline & & Average & 129.3 & 17.1 & 2.5 & 28.7 & 3.5 & 330.7 & 9.9 & 0.604 & 3.2 \\
\hline \multirow{4}{*}{$\begin{array}{l}\mathrm{T}-0.3- \\
25-2 \%\end{array}$} & \multirow{4}{*}{55} & & 90.14 & 21.2 & 2.3 & 46.6 & 4.0 & 643.7 & 10.1 & 0.762 & 1.8 \\
\hline & & & 122.7 & 29.7 & 3.3 & 53.0 & 4.6 & 680.5 & 10.7 & 0.633 & 1.5 \\
\hline & & & 139.3 & 21.2 & 2.3 & 38.1 & 3.3 & 877.6 & 13.8 & 1.840 & 4.4 \\
\hline & & Average & 117.4 & 24.0 & 2.6 & 45.9 & 4.0 & 733.9 & 11.6 & 1.078 & 2.6 \\
\hline \multirow{4}{*}{$\begin{array}{l}\text { T- } 0.3- \\
25-3 \%\end{array}$} & & & 121.8 & 30.2 & 2.5 & 64.8 & 3.1 & 1167 & 10.8 & 1.615 & 3.4 \\
\hline & 55 & & 125.8 & 25.2 & 2.1 & 56.7 & 2.7 & 1133 & 10.5 & 1.098 & 2.3 \\
\hline & & & 142.1 & 32.7 & 2.7 & 68.1 & 3.3 & 1153 & 10.7 & 0.927 & 1.9 \\
\hline & & Average & 129.9 & 29.3 & 2.5 & 63.2 & 3.0 & 1151 & 10.7 & 1.213 & 2.5 \\
\hline
\end{tabular}


Table 4. Maximum tensile stress in the fiber and equivalent bond strength of UHP-FRC under impact loading

\begin{tabular}{ccccc}
\hline Test series & $l_{f} / d_{f}$ & $\sigma_{p c}(\mathrm{MPa})$ & $\sigma_{f p c}(\mathrm{GPa})$ & $\lambda \tau_{e q}(\mathrm{MPa})$ \\
\hline $\mathrm{T}-0.3-25-1 \%$ & 83 & 28.7 & 3.18 & 34.5 \\
\hline $\mathrm{T}-0.3-25-2 \%$ & 83 & 45.9 & 2.55 & 27.7 \\
\hline $\mathrm{T}-0.3-25-3 \%$ & 83 & 63.2 & 2.34 & 25.4 \\
\hline $\mathrm{S}-0.2-25-1 \%$ & 125 & 25.3 & 2.81 & 20.2 \\
\hline $\mathrm{S}-0.2-25-2 \%$ & 125 & 44.7 & 2.48 & 17.9 \\
\hline $\mathrm{S}-0.4-25-2 \%$ & 62.5 & 25.0 & 1.39 & 20.0 \\
\hline $\mathrm{S}-0.4-25-3 \%$ & 62.5 & 40.5 & 1.50 & 21.6 \\
\hline
\end{tabular}

